\title{
EGATEC: A new high-resolution engineering model of the global atmospheric electric circuit-Currents in the lower atmosphere
}

\author{
A. Odzimek, ${ }^{1,2}$ M. Lester, ${ }^{1}$ and M. Kubicki ${ }^{2}$ \\ Received 20 October 2009; revised 21 April 2010; accepted 7 May 2010; published 23 September 2010.
}

[1] We present a new high-resolution model of the Earth's global atmospheric electric circuit (GEC) represented by an equivalent electrical network. Contributions of clouds to the total resistance of the atmosphere and as current generators are treated more realistically than in previous GEC models. The model of cloud current generators is constructed on the basis of the ISCCP cloud data and the OTD/LIS lightning flash rates and TRMM rainfall data. The current generated and the electric resistance can be estimated with a spatial resolution of several degrees in latitude and longitude and 3 hour time resolution. The resistance of the atmosphere is calculated using an atmospheric conductivity model which is spatially dependent and sensitive to the level of solar activity. An equivalent circuit is constructed assuming the ionosphere and ground are ideal conductors. The circuit solution provides diurnal variations of the ionospheric potential and the GEC global current at the 3 hour time resolution as well as the global distributions and diurnal variations of the air-Earth current density and electric field. The model confirms that the global atmospheric electric activity peaks daily at $\sim 21$ UT. The diurnal variation of the ionospheric potential and the global current have a maximum at 12 and 21-24 UT in July and at 9 and 21 UT in December, and a global minimum at 3-6 UT independent of season. About $80 \%$ of the current is generated by thunderstorm convective clouds and $20 \%$ by mid-level rain clouds.

Citation: Odzimek, A., M. Lester, and M. Kubicki (2010), EGATEC: A new high-resolution engineering model of the global atmospheric electric circuit_Currents in the lower atmosphere, J. Geophys. Res., 115, D18207, doi:10.1029/2009JD013341.

\section{Introduction}

[2] The Engineering model of the Global ATmospheric Electric Circuit (EGATEC) was proposed to develop a novel engineering quasi-3D model of the Earth's DC global atmospheric electric circuit (GEC). EGATEC models the global electric circuit as a network of electrical elements using input from new observations, data sets and models.

[3] The GEC refers to the configuration of electric currents and fields in the Earth's atmosphere produced and affected by various processes operating in the Earth's atmosphere and the Earth's ionosphere-magnetosphere environment [Rycroft et al., 2000; Tinsley, 2008; Williams, 2009]. The main observable variables of the global circuit are: the airEarth current density, electric field (or electric potential gradient) at the Earth's surface and the ionospheric potential, which are subjected to both irregular and systematic diurnal and seasonal variations [Williams and Heckman, 1993;

\footnotetext{
${ }^{1}$ Department of Physics and Astronomy, University of Leicester, Leicester, UK.

${ }^{2}$ Polish Academy of Sciences, Institute of Geophysics, Warsaw, Poland.

Copyright 2010 by the American Geophysical Union. 0148-0227/10/2009JD013341
}

Adlerman and Williams, 1996; Harrison, 2004; Markson, 2007; Williams, 2009].

[4] Modelling the global atmospheric circuit has a long history since the concept was introduced by C.T.R. Wilson [Wilson, 1920] who identified thunderstorms and shower clouds as the sources for the global circuit. In the last century both analytical and numerical models of the global atmospheric circuit and related processes have been developed [e.g., Hays and Roble, 1979; Makino and Ogawa, 1984; Sapkota and Varshneya, 1990; Tinsley and Zhou, 2006] which treat these processes in some detail [Odzimek and Lester, 2009]. The majority of the models have been concerned with the flow of the electric current from thunderstorms, playing the role of the batteries driving the circuit through conduction currents and lightning, and the distribution of the electric potential in the vicinity of thunderstorms and mapping of the fields in the ionosphere. The fair-weather electric field has also been modelled, in those models cloudfree air was usually considered as typical fair weather conditions [e.g., Makino and Ogawa, 1984; Sapkota and Varshneya, 1990]. The role of other charging agents such as electrified precipitation and corona current has been pointed out and discussed by different authors [Wormell, 1930, 1953; Williams and Heckman, 1993; Soula and Chauzy, 1997; Williams and Sátori, 2004]. 
[5] In EGATEC the GEC is modelled as an equivalent electrical network (circuit) which is solved analytically or numerically by simulation using engineering software for simulations of electrical circuits. Representations of the GEC in the form of a simple electrical circuit have been used previously [Nisbet, 1983; Tinsley, 2008; Rycroft et al., 2000, 2007].

[6] Makino and Ogawa [1984] created a high-resolution circuit representation of the GEC, with current sources and atmospheric resistances distributed over the globe as a network of $72 \times 36$ branches based on a $5^{\circ}$-resolution geographical grid. The branches were connected in parallel between two nodes representing the ideally conducting ground and the ionosphere. Branches in the fair-weather area consisted of resistors and branches from the generator area included resistors and current sources. The amplitudes of these current sources, which ranged from 12.86 to $77.14 \mathrm{pA} / \mathrm{m}^{2}$, were related to the level of thunderstorm activity inferred from lightning flash rates detected by the sensors on the Defense Meteorological Satellite Programme. The diurnal variation of the GEC in Universal Time was calculated by modulation of this source distribution by a 3-hour half-width gaussian centred at 16 LT. Sapkota and Varshneya [1990] constructed a similar circuit as a GEC representation and incorporated a more realistic conductivity model using a non-uniform aerosol concentration distribution over the globe.

[7] Price et al. [1997] used the International Satellite Cloud Climatology Project data to estimate the surface area of deep convective clouds and stratus and nimbostratus driving electric currents through lightning and corona discharges in their GEC model. They were the first to create a model where the GEC global current was related to the actual (observed) surface area of generator clouds.

[8] The recent availability of various new and useful data sets and models has considerably improved the ability to model the GEC. In this paper we use such data and models to create a high-resolution model of lower atmosphere current generators, and secondly, to simulate the electric currents and fields in the lower atmosphere due to these atmospheric generators, i.e. the generators that are believed to maintain the potential of the ionosphere at $\sim 200-300 \mathrm{kV}$ [Markson, 1985, 2007]. We aim to treat clouds more realistically, by using the observed cloud distribution over the globe and by taking into account the contribution of clouds to the total atmospheric resistance and to the current that drives the global circuit. We follow the idea of the representation of the GEC by a high-resolution electric circuit. We assume the ionosphere to be an equipotential surface at $60 \mathrm{~km}$ altitude which allows an analytic solution of the circuit.

[9] Section 2 describes the data sets and models we use as input to our GEC model. Sections 3-5 describe the equivalent electrical circuit structure and the construction of the cloud generators. Model calculations results and comparison with observations are presented and discussed in Sections 6-7.

\section{EGATEC Model Input}

[10] The main current generators represented by current sources in the model are 1) due to thunderstorm activity, and 2) due to non-thunderstorm electrical activity. Algorithms for the calculation of the geographical distribution and amplitudes of these current sources are developed on the basis of cloud and atmospheric data and models currently available. Details of how these data contribute and are used in the model are described in the following paragraphs. Prior to utilising in the model the original spatial resolution of the input data is converted to the EGATEC grid resolution. The time resolution of the data determines the time resolution of the model.

\subsection{Lower Atmosphere Conductivity}

[11] Tinsley and Zhou [2006] developed a novel atmospheric conductivity model which can be conveniently applied in EGATEC. The model includes: 1) ion production rates due to cosmic rays, 2) ion production rates due to radioactive radon ${ }^{222} \mathrm{Rn},{ }^{220} \mathrm{Rn}$ and particle radiation coming from the Earth, 3) the Global Aerosol Data Set (GADS), which provide tropospheric aerosol concentration distribution and altitude profiles [Hess et al., 1998], and 4) a stratospheric aerosols geographic distribution and altitude profile model. The conductivity model is sensitive to the level of solar activity as the model ion production rates by cosmic rays are parametrised by low and high solar activity (at solar minimum and solar maximum conditions). Also, the concentration of stratospheric aerosols can be enhanced at higher volcanic activity in this model. In addition, two different tropospheric aerosol concentration distributions are taken from the GADS data to recreate the aerosol distribution over the globe for summer and winter (July and December).

[12] The conductivity is calculated according to the standard formula $\sigma=e\left(\mu_{-} n_{-}+\mu_{+} n_{+}\right)=2 e \mu n$, where $e$ is one elementary electric charge, $\mu$ is the ion mobility, and $n$ is the ion concentration, assuming that throughout the atmosphere positive $(+)$ and negative $(-)$ ions having equal concentrations and mobility. Swider [1985] gives values of the atmospheric positive and negative ion mobility in four altitude ranges, $0-15 \mathrm{~km}, 15-35 \mathrm{~km}, 35-50 \mathrm{~km}, 50-70 \mathrm{~km}$ (15-45 km and $45-70 \mathrm{~km}$ for the negative ion mobility). As up to $35 \mathrm{~km}$, which includes the most resistant portion of the atmosphere, these positive and negative mobilities are equal we take an average ion mobility of the positive and negative mobilities in those altitude ranges. Next the calculations of ion concentration follows the procedure described in Tinsley and Zhou [2006]. The ion production rates, $q$, and mobility at standard temperature and pressure (STP) are converted to numbers at height, $z$, by scaling with neutral concentration $N$ at height $z: q(z)=q_{S T P} N(z) / N_{L}$ and $\mu(z)=q_{S T P}(z) N_{L} / N(z)$, $N_{L}$ being the Loschmidt constant. Zhou and Tinsley [2007] point out that this type of conversion may not be appropriate for the whole range of atmospheric temperatures and pressures, although, using more realistic formula, e.g. their expression (A9), does not lead to very significant differences in our calculations. In the conversion from STP values we use the neutral number concentration $N(z)$ obtained from the International Mass-Spectrometer-Incoherent-Scatter (MSIS-E-90) model [Hedin, 1991].

[13] In EGATEC we also take into account cloud conductivity which is usually lower than that of free air [MacGorman and Rust, 1998]. For simplicity we assume that the concentration of condensation nuclei in all types of clouds is $2 \times 10^{2} \mathrm{~cm}^{-3}$ (as in work by Makino and Ogawa 
[1984] and Zhou and Tinsley [2007]), and the ion attachment rate of $1.6 \times 10^{-4} \mathrm{~cm}^{-3} \mathrm{~s}^{-1}$. This will lead to a reduction of conductivity within clouds by a factor of a few to a few tens, compared to the free air conductivity. Below thunderclouds the conductivity can increase due to the production of ions by corona discharges [Sapkota and Varshneya, 1990]. In the case of corona discharges the conductivity at the ground will be twice higher than normal conductivity and above the ground it would change with altitude according to equation (4) of Sapkota and Varshneya [1990].

\subsection{Clouds}

[14] The International Satellite Cloud Climatology Project (ISCCP) data sets are a vast source of information about the global distribution of cloud radiometric properties and of atmospheric temperature and humidity (http://isccp.giss. nasa.gov) [Rossow and Schiffer, 1991]. ISCCP data from the period 1981-2007 are available from the NASA Langley Research Center Atmospheric Science Data Center, http:// eosweb.larc.nasa.gov. The ISCCP cloud data are obtained by satellite measurements of radiance in the infra-red (IR) and near infra-red range. By the IR technique clouds can be detected and divided into three main altitude categories: high-, mid-, and low-level clouds. Furthermore, the satellite instruments make measurements in the optical range during daytime. By the optical (VIS) measurements more cloud categories can be resolved by comparing cloud optical thickness versus cloud top pressure, and, as a result, nine different cloud categories can be distinguished: deep convective, cirrocumulus, cirrus (the high-level), nimbostratus, altostratus, altocumulus (the mid-level), stratus, stratocumulus and cumulus (the low-level), clouds, i.e. three categories within each IR category which is based only on the estimate of the cloud top pressure. Results from the optical measurements are considered to be more reliable than the infra-red [Rossow et al., 1996].

[15] EGATEC uses the ISCCP D1 data series, created following improvements of cloud categorisation algorithms used in the original ISCCP $\mathrm{C} 1$ data series [Rossow and Schiffer, 1999]. Each ISCCP D1 data set provides 202 cloud and atmospheric variables at 3 -hour resolution in the 5969-cell ISCCP grid (of $2.5^{\circ}$ resolution in geographic latitude and variable number of cells at each latitude at $280 \mathrm{~km}$ resolution: from 3 equal-area cells at geographic poles, each $\sim 80,000 \mathrm{~km}^{2}$ to 144 equal-area cells at the equator, each $\sim 77,000 \mathrm{~km}^{2}$ ). At $0,3,6, . ., 21$ UT the IR cloud data are available for $\sim 85-98 \%$ fraction of the globe, and the VIS-adjusted data for $\sim 40 \%$ of the globe.

[16] At this stage of development of EGATEC the following ISCCP D1 variables are used: 1) percentage of clear sky area 2) percentage of area covered by clouds (for the three "level" categories and the nine "optical" categories if VIS-adjusted data are determined), 3) cloud top height, and 4) precipitable water for high, middle, and low altitudepressure level - per an ISCCP cell. Since the ISCCP cannot provide the distribution of clouds over the whole globe, as required for a complete GEC model, an algorithm is applied to interpolate the ISCCP variables to those cells where no data is available and, partly, to interpolate the VIS-adjusted results over a larger area of the globe. This algorithm is described in more detail in Appendix A.
[17] ISCCP grid elements are tagged with a mean topographic altitude, land cover fraction and vegetation type. The mean topographic altitudes are used to calculate the topographic map on the EGATEC grid.

\subsection{Lightning and Rainfall}

[18] Lightning and rainfall can particularly be associated with occurrence of electrified clouds such as thunderstorm or shower clouds. Data obtained by the Optical Transient Detector (OTD) over the 1995-2000 period and the Lightning Imaging Sensor (LIS) from 2003 onwards are the largest source of information on global lightning activity at present [Christian et al., 2003]. Geographical distribution of hourly, monthly and yearly rates of lightning flash density for the period 1 April 1995 to 12 December 2006 are available from http://thunder.nsstc.nasa.gov. The data are provided in a geographical grid of $2.5^{\circ}$ resolution in longitude and latitude. We use the gridded Low Resolution Time Series (LRTS) and the gridded Low Resolution Annual/Diurnal Climatology (LRADC) data sets. LRTS provides current (daily) lightning flash density, per an OTD/ LIS cell, and LRADC provides an average 2-hour lightning flash density per cell, on any day of the year. Furthermore, rainfall is obtained from the gridded Tropical Rainfall Measuring Mission [Kummerow et al., 1998] 3B42 data (TRMM-Adjusted Merged-Infrared Precipitation). The TRMM data sets are available from the Goddard Distributed Active Archive Center at http://daac.gsfc.nasa.gov. The rainfall estimates are gridded on at 3-hour temporal resolution, similar to the ISCCP data, and $0.25^{\circ}$ spatial resolution in a belt extending from $50^{\circ} \mathrm{N}$ to $50^{\circ} \mathrm{S}$ latitude $\left(40^{\circ} \mathrm{N}\right.$ to $40^{\circ} \mathrm{S}$ prior to February 2000, http://trmm.gsfc.nasa.gov/3b42.html). Both the lightning flash rate and the rainfall level is further used in the model to provide more information for an adequate division of the ISCCP clouds into current generator and non-generator categories and to calculate equivalent DC current generators (Section 4).

\section{Representation by Electrical Circuit}

[19] The EGATEC circuit is a network of branches consisting of electric elements (resistors and current sources) fixed between a discrete number of nodes representing chosen locations in the Earth's atmosphere or ionosphere, covering the whole globe and altitudes up to ionospheric; in this model version the ionosphere is at $60 \mathrm{~km}$ (Figure 1). The circuit nodes are enumerated subsequently as the geographic longitude $\lambda$, colatitude $\theta$, and altitude $z$ increase. The number of nodes depends on the resolution of the circuit - in the direction of increasing $\lambda$ there are $N_{\text {lon }}=$ $360^{\circ} / D_{\text {lon }}$ nodes enumerated by index $i=0 . . N_{\text {lon }}-1$. Similarly, in the direction of increasing $\theta$ there are $N_{\text {lat }}=180^{\circ} / D_{\text {lat }}$ nodes enumerated by index $j=0 . . N_{\text {lat }}-1 ; D_{\text {lon }}$ and $D_{\text {lat }}$ are the circuit resolutions in degrees in longitude and latitude, respectively. This creates $N_{\text {lon }} \times N_{\text {lat }}$ circuit branches centred at geographical longitudes $\lambda_{i}=D_{\text {lon }}(i+0.5)$ and colatitudes $\theta_{j}=D_{\text {lat }}(j+0.5)$. In the current model version $D_{\text {lon }}=D_{\text {lat }}=$ $5^{\circ}$, as in the models of Makino and Ogawa [1984], Sapkota and Varshneya [1990], and Tinsley and Zhou [2006]. All the branches are connected to node " 0 " representing the ground at potential zero (i.e. assumed to be ideally conducting) and node " 1 " representing an equipotential (ideally conducting) 


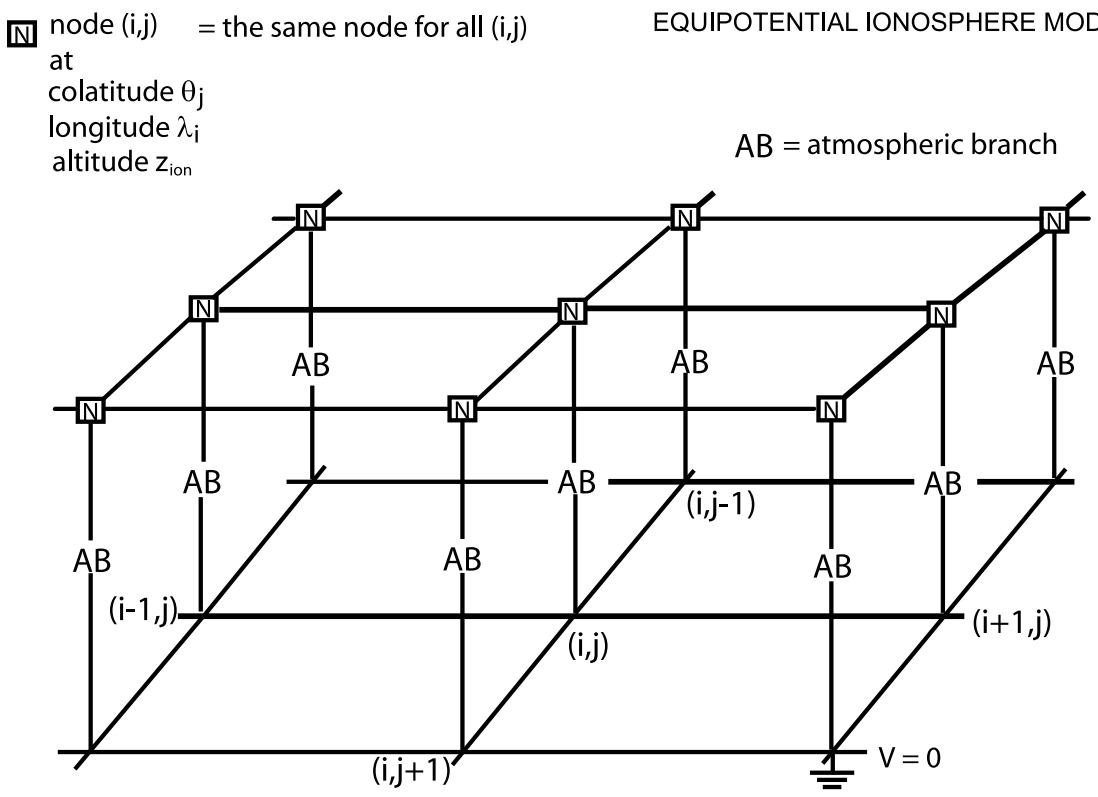

Figure 1. The main structure of the EGATEC circuit. The circuit is oriented geographically. $N_{\text {lon }} \times N_{\text {lat }}$ atmospheric branches $(\mathrm{AB})$ are arranged with increasing geographic latitude and colatitude, $72 \times 36$ branches are created at $5^{\circ}$ resolution in geographic longitude and latitude. In this model the ionosphere is considered to be an equipotential surface so all branches are connected to the same node representing the ionosphere and the node representing the ideally conducting ground.

ionosphere, at a constant potential in relation to the ground $V_{I}$ which has to be found.

[20] The surface area of a branch at a longitude $\lambda_{i}$ and colatitude $\theta_{j}$ decreases with increasing geographic latitude $\varphi_{j}=90^{\circ}-\theta_{j}$

$$
A^{i j}=\frac{2 \pi R_{E}^{2}}{N_{l o n}}\left(\sin \varphi_{j}-\sin \varphi_{j+1}\right)
$$

where $R_{E}$ is the Earth's average radius of $6371.2 \mathrm{~km}$. In the case of $5^{\circ}$ resolution in latitude and longitude the branches' surface area ranges from $13,500 \mathrm{~km}^{2}$ at polar regions to $309,000 \mathrm{~km}^{2}$ near the equator. This is usually too large area compared even to very large convective systems. Therefore it is allowed in the model that a single circuit branch has up to seven sub-branches, each representing an area covered by the cloud types 1-7, introduced in the next section. Within each area the variations in the lateral dimensions are suppressed and all model variables are reduced to their vertical components. Area types 1, 2, 3, 6, 7 are represented by one resistor. Area types 4 and 5 are represented by a series of three resistors and a current source in parallel with the middle resistor, as shown in Figure 2. The current source is calculated according to the description in the next section using the input described in Section 2.

[21] Columnar resistances, i.e. the resistances of the portion of the atmosphere of a unit surface area, at a branch $(i, j)$ and cloud area type $a=1, \ldots, 7$, from height $z_{1}$ to $z_{2}$ can be calculated by integration of $1 / \sigma(z)$ over the height interval

$$
\tilde{R}_{a}^{i j}(z 1, z 2)=\int_{z_{1}}^{z_{2}} \frac{d z}{\sigma_{a}^{i j}(z)}
$$

and the resistance of the sub-branch from height $z_{1}$ to $z_{2}$ equals the columnar resistance $\tilde{R}_{a}^{i j}\left(z_{1}, z_{2}\right)$ divided by the sub-branch surface area $S_{a}^{i j}$ which is a fraction of $A_{i, j}$, and is obtained from the ISCCP data.

$$
R_{a}^{i j}(z 1, z 2)=\frac{\tilde{R}_{a}^{i j}(z 1, z 2)}{S_{a}^{i j}}
$$

In the following sections $R_{a}^{i j}$ or $\tilde{R}_{a}^{i j}$ denote the resistance or columnar resistance, respectively, over the total altitude range in the branch from ground level $z_{g}$ to the ionosphere height $z_{\text {ion }}=60 \mathrm{~km}$.

\section{Lower Atmosphere Current Generators}

[22] Mach et al. [2009] have recently published a summary of the results of measurements of electric currents above thunderstorm systems and storms without lightning in the southeastern US, western Atlantic Ocean, the Gulf of Mexico, central America, central Brazil and the South Pacific north of Australia. Their peak values of the current density range from -2.0 to $+33 \mathrm{pA} / \mathrm{m}^{2}$, with a mean value of $+1.9 \mathrm{pA} / \mathrm{m}^{2}$ and the median $+0.6 \mathrm{pA} / \mathrm{m}^{2}$. Calculated total currents range from -1.3 A to +9.4 A per storm, with a mean value of $+0.8 \mathrm{~A}$. These observations confirm that in the majority of cases electric currents flow upwards and charge the ionosphere positively.

[23] Wilson [1920] proposed that shower clouds could positively charge the ionosphere, as discussed by Williams and Sátori [2004]. Electric currents have also been discovered above active snowstorms [Anderson, 1966]. In the work by Mach et al. [2009] over 1/3 of the storms with current did not have lightning. In general much less is known about the electrical activity of non-thunderstorm clouds and what their role is in the global circuit. Much of what is known are results of investigations in the $50 \mathrm{~s}$ and 60s in the Soviet Union [Imyanitov et al., 1974; 


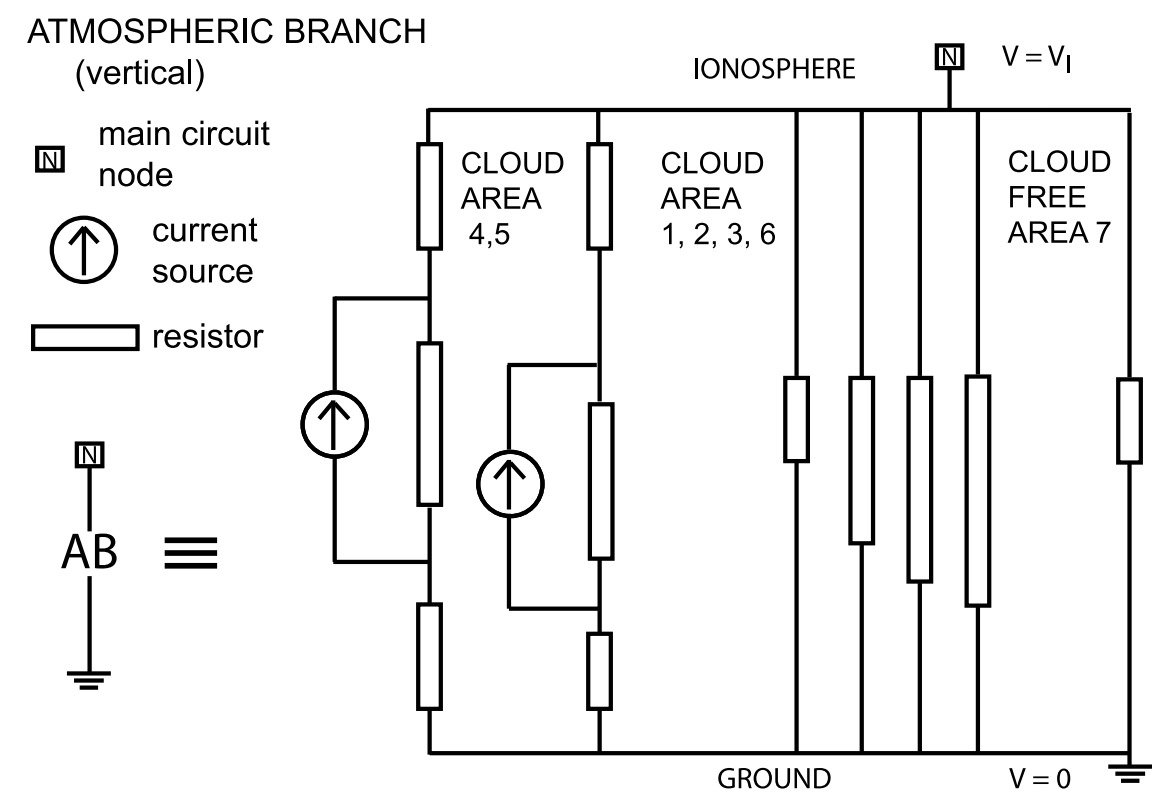

Figure 2. The atmospheric branch of the EGATEC circuit. Each circuit branch consists of 1-7 subbranches representing area covered by cloud generator type 4 and 5 , and covered by passive cloud type $1,2,3,6$, and cloud-free area 7. Passive areas are represented by one resistor, and generator areas are modelled by a series of three resistors and a current source in parallel with the middle resistor. The electric current flowing in a sub-branch is described by equation (8).

MacGorman and Rust, 1998, chapter 4]. Chalmers [1958] modelled altitude profiles of the electric potential in snow and rain nimbostratus clouds, created on the basis of electric current density and potential gradient measurements under these clouds in the UK. More recently, Harrison and Nicoll [2008] have considered a role for non-thunderstorm rain clouds in the seasonality of the global circuit on the basis of the air-Earth current density measurements and the observations of the weather conditions at Lerwick, UK, and analysis of nimbostratus clouds in ISCCP data.

[24] Imyanitov and Shifrin [1962] in their Figures 21-23 show representative profiles of the electric field through layer clouds, e.g. stratus, stratocumulus, altostratus, nimbostratus and cirrostratus. They describe clouds as "charge generators", as the clouds, according to their measurements, acquire significant amount of charge. In the characteristic profiles in Figure 23 of Imyanitov and Shifrin [1962] the electric field near the ground under nimbostratus has the opposite direction to that in the case of stratus, stratocumulus and altostratus, for which the field near the ground has the same direction as in cloud-free area. The cirrostratus case in this survey seems peculiar since the electric field within the cloud is negative, and differs from profiles of stratus, stratocumulus and altostratus. The profiles for stratus, stratocumulus and altostratus suggest that the increased electric field may be the result of reduced cloud conductivity. According to Gauss' law, charge layers will be created at the top and bottom of a cloud, i.e. where the electric field gradients are large [MacGorman and Rust, 1998; Zhou and Tinsley, 2007]; the charge density in those layers have been measured recently by Nicoll and Harrison [2009] in layer clouds. However, the vertical profile of the electric field through the nimbostratus cloud from Imyanitov and
Shifrin [1962] and some Ns cases described by Chalmers [1958] suggest that the electrical structure of these clouds, which appear due to charged precipitation from the clouds, is that the clouds can produce positive electric current flowing to the ionosphere. Therefore they also can be considered as generator clouds.

[25] According to Imyanitov and Shifrin [1962], in layer clouds the charge structure is usually dipolar or unipolar, with the positive dipole type observed most frequently. They report that in $\sim 7-10 \%$ cases an inverted charge structure is observed, and, usually the charge structure becomes more complicated in mid-level clouds, compared to low-level clouds, and as the cloud thickness grows. Moreover, the charge and electric field structure in clouds depend on the microphysical properties of the cloud such as the temperature and phase of the cloud particles as different electric field profiles are observed in warm, cold or mixedphase clouds [Chalmers, 1958; Imyanitov et al., 1974; MacGorman and Rust, 1998].

[26] Mach et al. [2009] also estimate 7\% of cases in their survey, of thunderstorm systems producing downward current, i.e. discharging the GEC. Another category of systems that may drive significant downward currents are stratiform areas of Mesoscale Convective Systems. Mesoscale Convective Systems are $\sim 10-100$ thousand $\mathrm{km}^{2}$ conglomerates consisting of both convective and stratiform clouds and precipitation [Houze, 1993]. The stratiform areas produce lightning and sprites [Lyons, 2006], and due to very large surface area are also expected to produce significant conduction currents. The contribution of these systems to the global circuit is still a subject of investigation [Stolzenburg and Marshall, 2008]. We do not consider such effects in our model at this stage. 
Table 1. Categorisation of Clouds in EGATEC ${ }^{\mathrm{a}}$

\begin{tabular}{|c|c|c|c|}
\hline $\begin{array}{l}\text { Area } \\
\text { Type }\end{array}$ & $\begin{array}{l}\text { ISCCP VIS } \\
\text { Cloud Data }\end{array}$ & ISCCP IR Cloud Data & $\begin{array}{c}\text { Other } \\
\text { Conditions }\end{array}$ \\
\hline 1 & $\mathrm{Ci}, \mathrm{Cs}$ & High-level other than 4 & - \\
\hline 2 & Ac, As & Mid-level other than 5 & - \\
\hline 3 & $\mathrm{Cu}$ & Low-level other than 6 & - \\
\hline 4 & $\mathrm{Cb}$ & $\begin{array}{l}\text { High-level, TRMM }>0 \\
\text { or PWH+PWM+PWL }>1.0\end{array}$ & $\operatorname{LRTS}_{N}>1$ \\
\hline 5 & Ns & $\begin{array}{l}\text { Mid-level, TRMM }>0 \\
\text { or PWM+PWL }>0.5\end{array}$ & - \\
\hline 6 & $\mathrm{Sc}, \mathrm{St}$ & Low-level, PWL > 0.3 & - \\
\hline 7 & None & None & - \\
\hline
\end{tabular}

${ }^{\text {a}}$ Six types of areas covered by clouds are distinguished and a cloud-free area.

\subsection{Generator and Passive Clouds}

[27] It is further considered in this model that deep convective clouds and mid-level nimbostratus clouds can generate electric current and most actively contribute to the global current flowing in the global circuit. Thus the division between the generator and passive (all remaining) clouds is made accordingly. By using the input cloud, lightning and rainfall data we divide each circuit cell into seven types: area covered by: 1. High-level clouds such as cirrus (Ci), cirrostratus (Cs), 2. Middle-level altocumulus (Ac) and altostratus clouds (As), 3. Low-level cumulus clouds $(\mathrm{Cu}), 4$. Deep convective clouds such as cumulonimbus $(\mathrm{Cb}), 5$. Middle-level layer clouds such as nimbostratus clouds (Ns), 6. Low-level clouds such as stratocumulus (Sc) and stratus (St), and 7. Cloud-free area, where no clouds are detected.

[28] If the ISCCP optical data are determined for the cell such division is straightforward. If the case when only IR data are determined an auxiliary procedure follows. It is assumed that rainfall or larger magnitude of precipitable water (taken from ISCCP data) may be an indication of the presence of convective or shower clouds. In these cells where TRMM data are determined the presence of rainfall will support the presence of generator clouds and in the absence of rainfall clouds will be categorised as passive. In those cells where the TRMM rainfall is not determined certain thresholds of the ISCCP precipitable water are applied to categorise the IR high-, and mid-level clouds into the generator (4-5) and passive (1-3 and 6) cloud categories: in generator clouds 4 the sum of precipitable water high-, mid- and low- level must exceed 1.0, and in clouds 5 the sum of precipitable water at mid- and low- levels must exceed 0.5 ; the thresholds have been roughly estimated by analysing the precipitable water levels for VIS-adjusted cloud data. In addition, to ensure that thunderstorms were likely to occur in the area, the number of flashes per day derived from the OTD/LIS LRTS flash rate density, LRTS $_{N}$, will have to be larger than 1 . Table 1 summarises how the clouds are categorised and what additional conditions and thresholds are used.

[29] Furthermore, the cloud altitude range is estimated as follows: if the cloud top altitude is determined in ISCCP data then this value is associated with clouds of the highest level occurring in the cell, otherwise, and for all the remaining cloud species, the cloud top and base altitude are prescribed. The cloud top $z_{t}$ is set to be a function of geographic latitude and ranges from larger values at the equator and lower values at polar latitudes. The function is $z_{t}=z_{t}^{p l}+\left(z_{t}^{e q}-z_{t}^{p l}\right)$ $\cos \varphi$, where $\varphi$ is the geographic latitude, $z_{t}^{e q}-$ cloud top height at equator, and $z_{t}^{p l}$ - cloud top at geographic poles. Different $z_{t}^{p l}$ and $z_{t}^{e q}$ are assigned to different types of clouds. In addition, for each cloud category, a constant altitude $z_{b}$ is assigned for the cloud base (Table 2). The cloud altitude range will be used in calculation of the columnar resistance and in the case of generator clouds - to calculate the height of main charge layers in these clouds and determine the altitude of equivalent DC current generators.

\subsection{Cloud Current Generator Models}

[30] The current generated by generator clouds is modelled in EGATEC by equivalent current generators shown schematically in Figure 2. Willett [1979] discusses the representation of the thunderstorm current generators in more detail and argues that a current source is a more appropriate electrical representation for thunderclouds compared to the representation by voltage sources. We apply the same approach to non-thunderstorm current generators.

[31] Probably the most problematic task in GEC modelling is the accurate prediction of the amplitude of these equivalent current sources and taking into account correctly the contribution of processes involved in the charge transfer from the cloud to ground or the ionosphere.

[32] In this model the current source representing a cloud current generator is estimated as follows. The source, for either convective or non-thunderstorm generator (type $a=$ $4,5)$ will be fixed in parallel with the source's internal resistance between nodes related to the locations of the two main charge layers within the cloud. We will assume the simplest dipolar charge structure in both convective $(a=4)$ and middle-level $(a=5)$ shower clouds, and construct the current source to be a DC equivalent of currents driven by the cloud due to charge separation inside the cloud. For simplicity we assume that the distance between the cloud charge layers will be proportional to the cloud height, and moreover, that both the lower, negative, charge layer height $z_{n}$ and higher, positive, charge layer height $z_{p}$, are in the following relation with the cloud top and base heights: $z_{n}=$ $z_{b}+0.45\left(z_{t}-z_{b}\right)$ and $z_{p}=z_{b}+0.85\left(z_{t}-z_{b}\right)$, where $z_{t}$ is the cloud top altitude and $z_{b}$ cloud base altitude (Table 2). The real altitude of the bottom charge layer is usually determined by temperature and lies between $0^{\circ} \mathrm{C}$ and $-20^{\circ} \mathrm{C}$ isotherms, or 5-10 km for thunderclouds. Our estimate based up on the expression for $z_{n}$ above gives values within this range.

[33] Next, we assume constant current density $j_{C}$ for cloud generators at a particular geographic latitude (Table 3). We

Table 2. Cloud Base and Top Altitudes ${ }^{\mathrm{a}}$

\begin{tabular}{cccc}
\hline Area Type & Cloud Type & Cloud Base $(\mathrm{km})$ & Cloud Top $(\mathrm{km})$ \\
\hline 1 & $\mathrm{Ci}$ & $6+2 \cos \varphi$ & $10+6 \cos \varphi$ \\
& $\mathrm{Cs}$ & $4+2 \cos \varphi$ & $6+2 \cos \varphi$ \\
2 & $\mathrm{Ac}, \mathrm{As}$ & 2.0 & $4+2 \cos \varphi$ \\
3 & $\mathrm{Cu}$ & 0.5 & $1+0.5 \cos \varphi$ \\
4 & $\mathrm{Cb}$ & 1.0 & $8+10 \cos \varphi$ \\
5 & $\mathrm{Ns}$ & 0.9 & $3+3 \cos \varphi$ \\
6 & $\mathrm{St}$ & 0.3 & 0.8 \\
& $\mathrm{Sc}$ & 1.0 & 2.0 \\
7 & None & - & -
\end{tabular}

${ }^{\text {a }}$ The top cloud altitude, which depends on geographic latitude $\varphi$, is used if ISCCP cloud top estimate is not determined. 
Table 3. Equivalent Generator Current Densities for Deep Convective Clouds at Land and Nimbostratus Clouds at Latitude $\varphi^{\mathrm{a}}$

\begin{tabular}{lcc}
\hline \multicolumn{1}{c}{ Cloud Type } & $j_{C}\left(\mathrm{pA} / \mathrm{m}^{2}\right)$ & $j_{L}$ \\
\hline Deep Convective & $50+150 \cos \varphi$ & LRADC Dependent \\
Nimbostratus & $12+18 \cos \varphi$ & - \\
\hline
\end{tabular}

${ }^{\mathrm{a}}$ The amplitude of the lightning current density depends on the LIS/OTD LRADC flash density as described in the text.

further assume that this amplitude also changes with latitude as $j^{p l}+\left(j^{e q}-j^{p l}\right) \cos \varphi$, to enforce higher intensities of cloud generators at lower latitudes related to the cloud height. Mach et al. [2009] acknowledge that there is a relation between currents produced by the storms and storm height but it seems to be more complicated. We assume that for deep convective clouds $j^{p l}=0.25 j^{e q}$ and mid-level generators $j^{p l}=0.40 j^{e q}$, where $j^{e q}$ is the amplitude at the geographic equator and $j^{p l}$ the amplitude at the geographical poles. We will also assume that the current density in the current sources generating current in clouds are stronger over land by $33 \%$ than over the oceans.

[34] In addition, for the non-thunderstorm cloud generators we assume that they not produce any lightning and that their equivalent current source amplitudes are at $20 \%$ of that for thunderclouds (Mach et al. [2010] obtained 25\% from their analysis). This magnitude of the current sources produces electric fields inside and below the cloud of the order of $10^{2}-10^{3} \mathrm{~V} / \mathrm{m}$, in agreement with values from [Imyanitov and Shifrin, 1962, Tables I and II and Figure 23d]. Table 3 shows the current densities associated with deep convective and middle-level cloud generators. These generators' current densities result in upward currents driving the global circuit that agree with the observed values concerning thunderstorms or shower clouds [e.g., Harrison and Nicoll, 2008; Mach et al., 2009].

[35] The contribution by lightning $j_{L}$ can be estimated from an average charge transferred by a lightning discharge and the rate of lightning flashes. The flash rates can be obtained locally by lightning detection systems, and global distributions and global rates can nowadays be obtained by optical detectors on satellites, the recent data coming from the OTD and LIS instruments [Christian et al., 1999, 2003]. The charges involved are less well known. For cloud-toground (CG) lightning, some estimates are obtained by integration of the return stroke current waveform modelled with the return stroke maximum value and time constants of the current rise and decay [Price et al., 1997]. Some estimates can also be obtained by determination of the charge moment change due to the discharges, from analysis of electromagnetic fields generated by the discharges in the Extremely and Very Low Frequency range. However, both techniques may not very efficient at determination of electric charge transferred during a continuing current phase of lightning discharges. The continuing phase is characterised by a much lower amplitude compared to the amplitude of the return stroke current but is of much longer duration (microseconds vs milliseconds) and thus much higher charge is transferred during this phase, especially by positive CGs [Rakov and Uman, 2003].

[36] Price et al. [1997] estimated $+33.3 \mathrm{C}$ as an average charge transferred by a negative cloud-to-ground lightning discharge, and $-42.8 \mathrm{C}$ by positive cloud-to-ground light- ning discharge, including multiple strokes and continuing currents in both cases. They assumed intra-cloud lightning does not contribute. Thus, taking into account the fractions of negative and positive cloud-to-ground discharges from Price et al. [1997], 0.85 and 0.15, respectively, the charge is $Q_{L}=(0.85 \cdot 33.3+0.15 \cdot(-42.8)) \simeq+6.6$ C. Rycroft et al. [2007] expect $Q_{L}$ to be much smaller. According to their simulations, a single stroke median $-\mathrm{CG}$ charges the ionosphere by $7 \mathrm{C}$ with respect to the ground, and $+\mathrm{CG}$ discharges it by $70 \mathrm{C}, 90 \%$ of the charge being transferred during the +CG's $90 \mathrm{~ms} 2 \mathrm{kA}$ continuing current. Further they assume there is $10-\mathrm{CG}, 0.7+\mathrm{CG}$ and $33 \mathrm{ICs}$ in every $\sim 44$ lightning discharges; $44 \pm 5$ being the latest estimate of global lightning flash rate by Christian et al. [2003]. Thus $Q_{L}$ in this case is only $\simeq+0.5 \mathrm{C}$. Later simulation by Rycroft and Odzimek [2010] showed that a $10 \mathrm{kA}$ intra-cloud discharge between lower negative charge layer and higher positive charge layer results in a discharge of the cloud by $2 \mathrm{C}$, i.e. such an IC discharge reduces charging of the ionosphere. As the average currents and polarity of IC discharges are even less known and studied than those of CG discharges this further complicates calculations of $Q_{L}$. In general this quantity is likely to be dependent on thunderstorm type and charge structure and the moment in a thunderstorm lifetime, as the storm starts with intra-cloud activity, after which cloud-to-ground activity also starts. Negative CGs prevail over + CGs but the + CGs and other atmospheric discharges such as sprites (not considered here) may be more frequent than an average level in mature stages of a thunderstorm, especially in thunderstorm systems such as MCSs.

[37] In our model we use the lightning frequency weighting as in work by Rycroft et al. [2007] and we set $Q_{L}=2 \mathrm{C}$ which is equivalent of an assumption that one - $\mathrm{CG}$ transfers $+18.7 \mathrm{C}$ (including multiple return strokes), one $+\mathrm{CG}$ transfers $-46.6 \mathrm{C}$ (taking into account that perhaps $\sim 30 \%+$ CGs may not have very strong continuing currents) and one IC transfers $-2 \mathrm{C}$. This is also equivalent to ICs not contributing at all and each $-\mathrm{CG}$ contributing $+14.5 \mathrm{C}$.

[38] Next, using the LRADC flash rate from OTD/LIS data, expressed in $\mathrm{m}^{-2} \mathrm{~s}^{-1}$, the current density due to lightning becomes $Q_{L} \cdot \operatorname{LRADC}\left(\mathrm{A} / \mathrm{m}^{2}\right)$. This value is next multiplied by the total columnar resistance of the generator area from the ground to the ionosphere divided by the resistance of the portion from $z_{n}$ to $z_{p}$, i.e. $j_{L, a}^{i j}=Q_{L} \operatorname{LRADC}{ }^{i j} \cdot R_{a}^{i j} / R_{2 a}^{i j}\left(\mathrm{~A} / \mathrm{m}^{2}\right)$ and $a=4$, to ensure that the contribution of the lightning current is not reduced by the equivalent current source's internal resistance.

[39] Finally, for cloud generators of type $a=4,5$, the current densities $j_{C, a}^{i j}$, and $j_{L, a}^{i j}$ add up to the total source current density $j_{0 a}^{i j}$. The current source amplitude is found by multiplying the total current density by the surface area $S_{a}^{i j}$ covered by those clouds in any circuit branch $(i, j)$

$$
j_{0 a}^{i j}=j_{C, a}^{i j}+j_{L, a}^{i j}, \quad I_{0 a}^{i j}=j_{0 a}^{i j} S_{a}^{i j} .
$$

\section{Circuit Solution}

[40] The circuit representing the GEC with an equipotential ionosphere from Figure 1 can be solved analytically. All $N_{\text {lon }} \times N_{\text {lat }}$ branches with their sub-branches, connected 


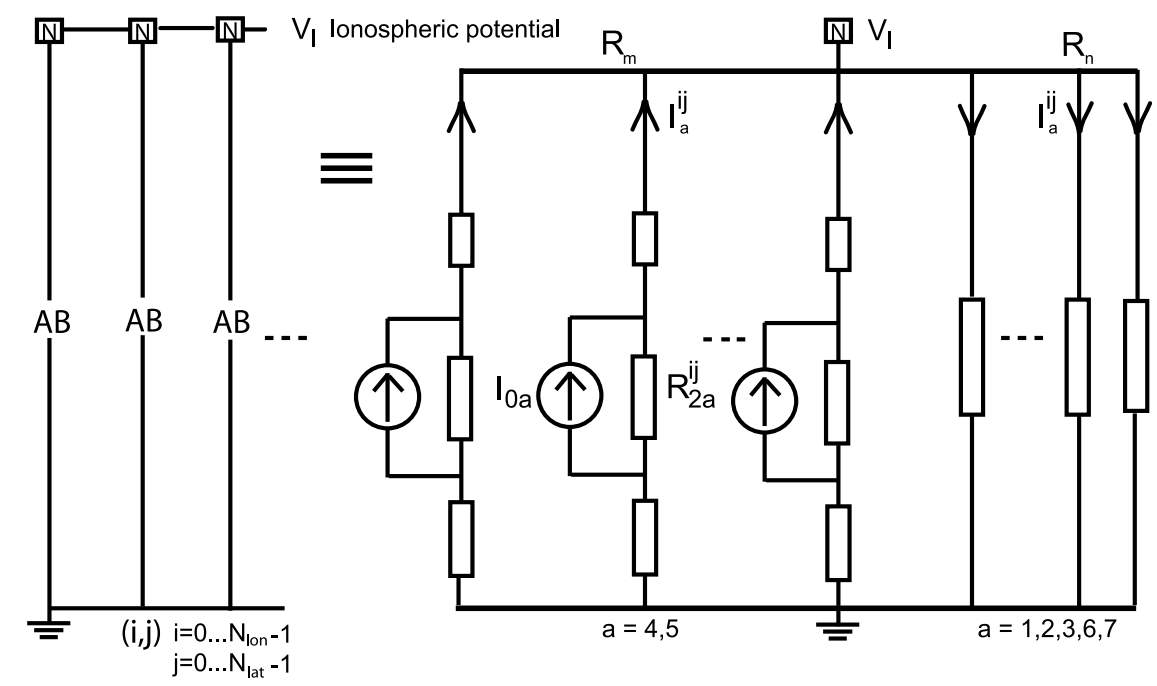

Figure 3. The equivalent circuit of the network shown in Figure 1 including branches shown in Figure 2. All sub-branches are connected in parallel between the ground and the ionosphere nodes. Sub-branches can be divided into generator and non-generator group. The current generated in the circuit is calculated according to equation (6). The ionospheric potential $V_{I}$ and the current flowing in the circuit are found from equation (7).

in parallel between nodes " 0 ", where the potential is set to be zero, and node " 1 " at the ionospheric potential $V_{I}$, can be divided into a generator group (all sub-branches with current sources) and passive group (all sub-branches consisting of resistances only), as shown in Figure 3.

[41] The resistance of the passive branches is the resistance $R_{F}$ and the resistance of all the branches is the total resistance of the atmosphere $R_{G}$, and they can be calculated according to equation (5)

$$
\frac{1}{R_{G}}=\sum_{i, j} \sum_{a=1}^{7} \frac{1}{R_{a}^{i j}}, \quad \frac{1}{R_{F}}=\sum_{i, j} \sum_{a=1,2,3,6,7} \frac{1}{R_{a}^{i j}}
$$

[42] The generator branches drive an upward current $I_{U}$ which equals the sum of the amplitudes of the individual current sources multiplied by the ratio of the internal resistance of the sources and the total resistance of each sub-branch

$$
I_{U}=\sum_{i, j} \sum_{a=4,5} \frac{I_{0 a}^{i j} R_{2 a}^{i j}}{R_{a}^{i j}}
$$

[43] The potential of node "1", i.e. the ionospheric potential $V_{I}$, and the current flowing in the global circuit $I_{G}$ can be found from $R_{G}, R_{F}$ and $I_{U}$ as follows

$$
V_{I}=\frac{I_{U}}{R_{G}}, \quad I_{G}=V_{I} R_{F}
$$

[44] When potential $V_{I}$ is calculated, the current flowing in each sub-branch can be found from

$$
I_{a}^{i j}=\frac{I_{0 a}^{i j} R_{2 a}^{i j}}{R_{a}^{i j}}-\frac{V_{I}}{R_{a}^{i j}}
$$

[45] In passive sub-branches $a=1,2,3,6,7$ the current equals $-V_{I} / R_{a}^{i j}$, i.e. the current there flows downward and discharges the ionosphere. Current flows upward and charges the ionosphere in sub-branches where $V_{I} / R_{a}^{i j}>I_{0 a}^{i j} R_{2 a}^{i j} / R_{a}^{i j}$, i.e. where the generator current overcomes the current imposed by the ionosphere. Current density $j_{a}^{i j}$ can be calculated either by using columnar resistances in equation (8), instead of resistances, or by dividing the current by the surface area of the sub-branch. Finally, the vertical electric field at height $z$ can be found from

$$
E_{a}^{i j}(z)=\frac{j_{a}^{i j}}{\sigma(z)}
$$

[46] In particular the electric field at the ground can be calculated by dividing the current density by the conductivity at the ground level $z_{g}: E_{0 a}^{i j}=j_{a}^{i j} / \sigma\left(z_{g}\right)$.

\section{Model Results}

[47] In this section we show results of model calculations for three days in each of the summer and winter of 2001 and 2005. The days that we considered were the 5 th, 15 th and 25 th of July and December. The ISCCP, TRMM and OTD/ LIS data have been retrieved for $0,3,6,9,12,15,18,21$ and 24 UT (0 UT the next day) for these dates, and cloud distributions calculated as described in Section 4. Summer and winter GADS aerosol distributions have been used in the conductivity calculations for the dates in July and December, respectively. In all cases low volcanic activity has been assumed. Furthermore, for the days in 2001 high solar activity parameters have been used for the ion production rates by cosmic rays and low activity parameters for 2005 .

\subsection{Composite Resistance, Current Density, and Electric Field}

[48] Since the conductivity in clouds is different than in free air and the altitude range of different types of clouds vary, the cloudy areas $1-6$ will be characterised by different 
columnar resistance. This also results in different current density and electric field (equations (8) and (9)). Thus each area 1-7 occurring in a circuit branch $(i, j)$ will be characterised by its own columnar resistance, current density and electric field. These values can be compared to observed values of the current or field at any location on the Earth, assuming we know the types of clouds that have been observed there, and assuming these types of clouds have been predicted in our model. Having the information about the cloud types and cloudiness at this location we can calculate a current density value or electric field value which should be characteristic for the current condition occurring at this location. We call this the composite columnar resistance, current density or the electric field.

[49] A composite value of the current density can be calculated in the following way. If the cloudiness and clear sky surface area, observed at a location of interest are $0 \leq$ $S_{c l}, S_{\text {sky }} \leq 1$, and the observed cloud species are $\left\{C_{a}, a=1.6\right.$, the composite electric current density or field is calculated as an area-weighted average: $J_{c}=S_{c l} J_{c l}+S_{s k y} J_{s k y}$ and $E_{c}=$ $S_{c l} E_{c l}+S_{s k y} E_{s k y}$, where the subscript sky refer to the current density or field value in the cloud-free area $a=7$ and ${ }_{c l}$ in the cloudy area $a=1.6$, depending on the type $C_{a}$. Composite columnar resistance can also be calculated as $1 / \tilde{R}_{c}=$ $S_{c l} l \tilde{R}_{c l}+S_{s k y} / \tilde{R}_{s k y}$, where $\tilde{R}_{c l}$ is the columnar resistance in the cloudy area and $\tilde{R}_{s k y}=\tilde{R}_{7}^{i j}$ is the columnar resistance in the cloud-free area. Layer clouds such as stratus or nimbostratus often occur as the only cloud species over an area but sometimes multi-level clouds occur at the same time, for example cumulus and mid-level cumuliform or cirriform clouds can occur simultaneously. In such case the columnar resistance, current density or field in the cloudy area is found as the model columnar resistance, current density or field for the lowest level cloud types which are observed (this choice is due to lower level clouds contributing more significantly to the resistance, field or current than higher level clouds).

[50] As an example we show the diurnal variation of the composite current density and electric field within one circuit branch $(i=4, j=7)$ centred at $22.5^{\circ} \mathrm{E}, 52.5^{\circ} \mathrm{N}$. This branch in fact represents $\sim 188,000 \mathrm{~km}^{2}$ in the central and eastern Europe. We compare the composite values with observations from the Geophysical Observatory in Świder, $21.25^{\circ} \mathrm{E}, 52.12^{\circ} \mathrm{N}$, Poland. The potential gradient (which equals in our coordinate system, by amplitude, the downward electric field) is measured at Świder using a radioactive collector placed $200 \mathrm{~cm}$ above ground level; the difference of the potential between the collector and the ground is amplified by an electrometer and the measured value is transmitted to a digital recording log system every 10 seconds. The maximum gradient which can be measured is $\pm 1500 \mathrm{~V} / \mathrm{m}$. A system including a flat Wilson antenna $(0.7 \mathrm{~m} \times 0.7 \mathrm{~m})$, connected to a 487 Keithley Inc. picoamperometer, measures the air-Earth current within the range $\pm 40 \mathrm{pA} / \mathrm{m}^{2}$, at the same time resolution $10 \mathrm{~s}$. Another system measures electric positive conductivity every minute, using a Gerdien aspiration condenser. The electric measurements are conducted simultaneously with continuous meteorological observations. In addition, measurements of the concentration of condensation nuclei (in the size range of $0.001-10 \mathrm{~mm}$ ) near ground level are taken three times a day at 6,12 and 18 UT. The electric field is recorded with errors less than
$10 \%$ and the errors in the conductivity measurements by the Gerdien method have errors lower than 20\% [Kubicki, 2005].

[51] First, we show the diurnal variation of cloudiness and cloud types observed at Świder and cloudiness calculated from the ISCCP cloud data (Figure 4), for 5, 15, 25 July and December 2001 and 2005. At the top of each plot in Figure 4 the main cloud type observed in Świder on the day is indicated. In most cases the observed level of cloudiness shows a correlation with the calculated cloudiness for the whole branch area which is a sign that the algorithms involved in ISCPP data works correctly, and that the use of ISCCP data sets in our model is justified.

[52] Figure 5 shows the diurnal variations of hourly averages of observed positive conductivity in Świder and the positive conductivity calculated from the model for the Swider circuit branch (the total conductivity in the model is twice the positive conductivity). The concentration of aerosol at the ground in this branch, according to the aerosol model used, is quite high, 33,400 thousand particles per $\mathrm{cm}^{3}$ in July and higher, 38,000 per $\mathrm{cm}^{3}$, in December. This is about twice higher than usually observed at Świder $\left(17,000\right.$ per $\mathrm{cm}^{3}$ annual average). On the days which we have chosen the aerosol concentration rarely exceeds 16,000 and only on one occasion, 25 July 2005 , it reaches $\sim 38,000$ at midday. This may explain that during the days when the weather conditions were closest to an ideal fair-weather conditions, e.g. 5 and 15 July 2005, the conductivity is higher by $\sim 1-4 \mathrm{fS}$, or comparable to the model values. This is not usually valid for the rest of the summer days, lower or comparable values are observed on 5, 15 July 2001 and 25 July 2005, and 25 July 2005 was a day with thunderstorms, which might affect the conductivity. On the winter days, the conductivity is lower than the model values by 1-3 fS. The higher aerosol level reducing effect on conductivity can be enhanced by the presence of fog, rain and snow, all of which were observed at Świder on these days.

[53] Figure 6 shows the variation of the calculated composite electric field, and for comparison, the electric field predicted by the model for cloud-free area in this branch, and the field observed at Świder (mean hourly values). We also compare variations of the composite current density, and the current density predicted by the model for cloudfree area in this branch, and the current density observed at Swider in Figure 7. As in the case of the conductivity, the observed values of the field and current density are naturally much more variable than model predictions but there are a few common features. In most cases the model diurnal variation fairly agrees with the observed and, moreover, the composite values are more appropriate for the description of the observed field or current density than just the fairweather value. In those cases where no generator clouds are observed, the best examples are the variations on 25 July 2005 or 5 December 2001. The largest differences between model and observed values occur for 5 July 2001 or 25 December 2001 and 5 December 2005. In the presence of electrified clouds over Świder (e.g. cumulonimbus on 25 July 2001 and nimbostratus on 15 December 2005 and 25 December 2001 and 2005) the model predicts field and current densities of opposite sign but tends to predict larger amplitudes. The electrical conditions at Świder in December are the most complicated to predict in EGATEC as the 
July 2001
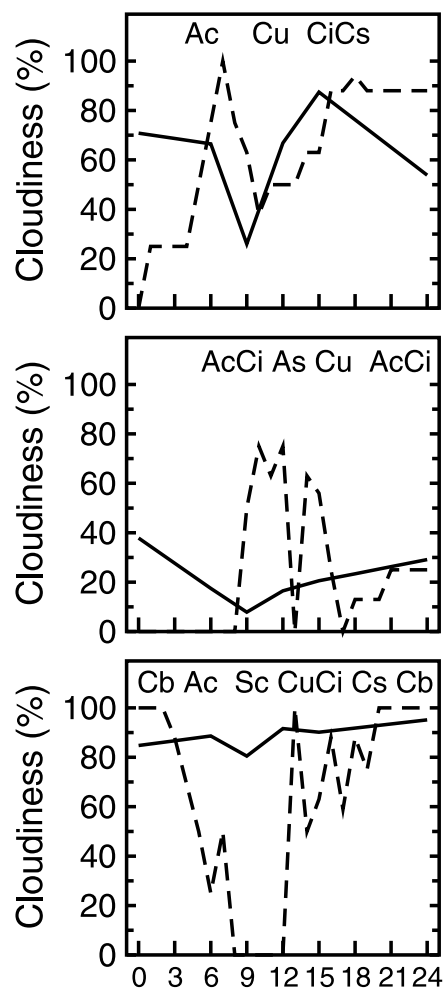

UT
July 2005
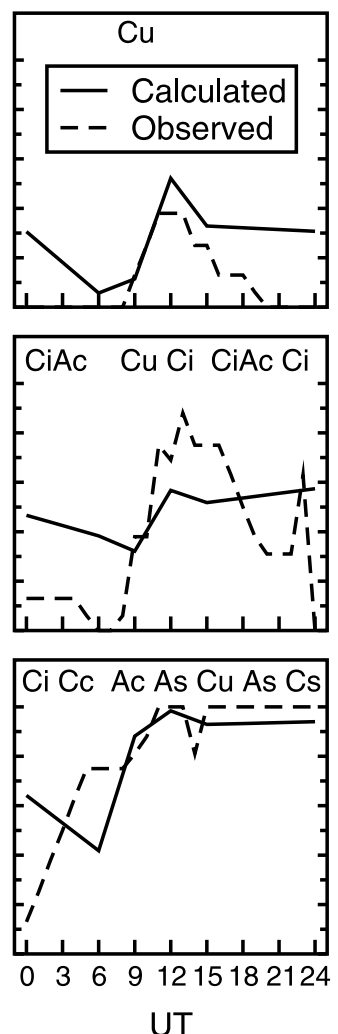

December 2001
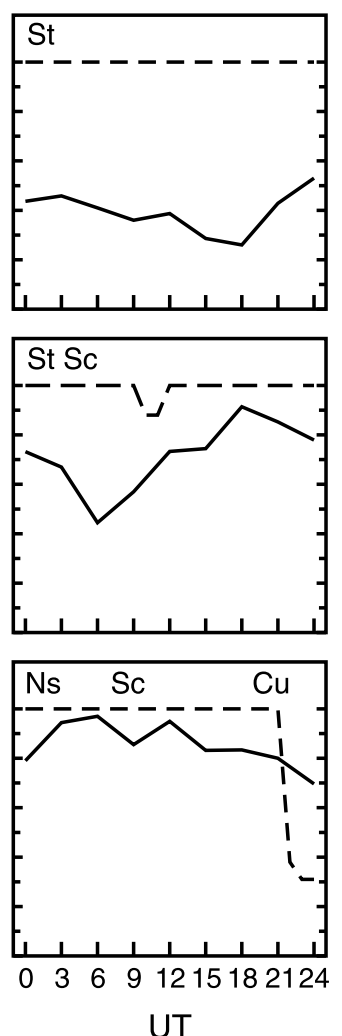

December 2005
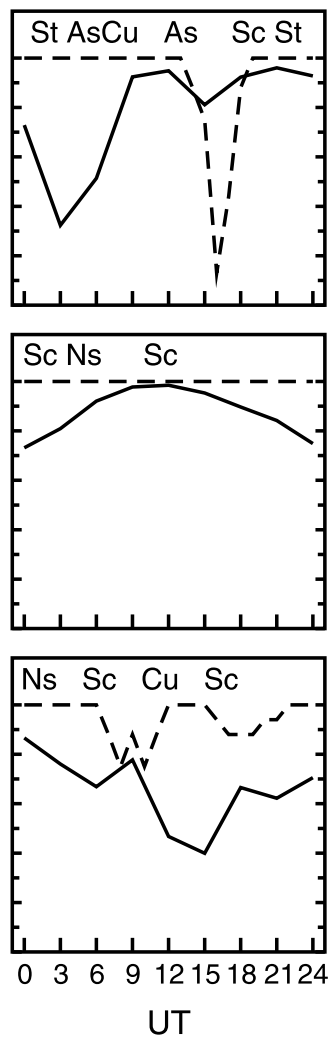

Figure 4. The diurnal variation of cloudiness in the EGATEC circuit branch centred at $22.5^{\circ} \mathrm{E}, 52.5^{\circ} \mathrm{N}$ and observed in Świder on (top) 5, (middle) 15, and (bottom) 25 of July and December 2001 and 2005.

weather occurring on these days at Świder involves fog, snowfall and rainfall from stratus clouds and such conditions are not treated specially in this model version. Our conclusion is that in future more sophisticated models of the electrical activity of various types of clouds are required. Such models should concern various types of clouds, and except regional differences also involve cloud microphysics. Furthermore, the model should be more efficient with modelling more realistic aerosol concentrations and, as a result, conductivities.

[54] In the next sections we show preliminary results from the EGATEC model that concern diurnal variations of the ionospheric potential and global current, and the geographical distribution of the current, and seasonal differences in the spatial variation of the current density and the electric field at the Earth's surface.

\subsection{Ionospheric Potential and Global Atmospheric Current}

[55] The generator current, ionospheric potential, global and fair-weather resistance and the current flowing in the GEC has been calculated according to equations (5)-(7) for the nine GEC model representations at 3 hour intervals on 5, 15, 25 July and December 2001 and 2005. Next, hourly and daily average values have been calculated.

[56] The mean average value of the ionospheric potential from the three days in July 2001 is $225 \mathrm{kV}$ and it is $238 \mathrm{kV}$ for December 2001. In 2005 the July average is $198 \mathrm{kV}$ and the December average is higher, $211 \mathrm{kV}$. Markson [2007] reports an observed maximum of the ionospheric potential in August-October and a rather stable level of the potential during the rest of the year. It is rather problematic to compare our modelled values with the secular variation from Markson [2007] shown in his Figure 4, especially that none of the reported measurements have been made in 2001 or 2005; just two measurements were made in 2002 and ten measurements in 2004. However, the measured potentials in 2004 were higher than in 2002.

[57] In the diurnal variations in Universal Time of ionospheric potential and the GEC global current there are two distinct maxima and minima, as shown in Figure 8. In July a maximum occurs at 12 UT and 21-24 UT, and a minimum at 3 UT and 15 UT. The 3 UT minimum is lower than that at 15 UT and the 21-24 maximum is higher than at 12 UT. In December maxima occur at 9 UT and 21 UT, and minima at 3-6 UT and 15 UT. The 3-6 UT minimum is lower than at $15 \mathrm{UT}$ and the 21 maximum is higher than that at 9 UT. This pattern of variation is almost identical in July and December of 2001 and 2005. The global and fair-weather resistance is shown in Figure 9. The total resistance of the atmosphere in the Tinsley and Zhou [2006] model was 160-180 $\Omega$. With the changes related to cloud conductivity the global resistance now ranges from 240-270 $\Omega$. Resistances in 2001 are higher than in 2005 which results in the differences between the 2001 and 2005 ionospheric potential and global current differences. The diurnal variation of the total resistance and 
July 2001
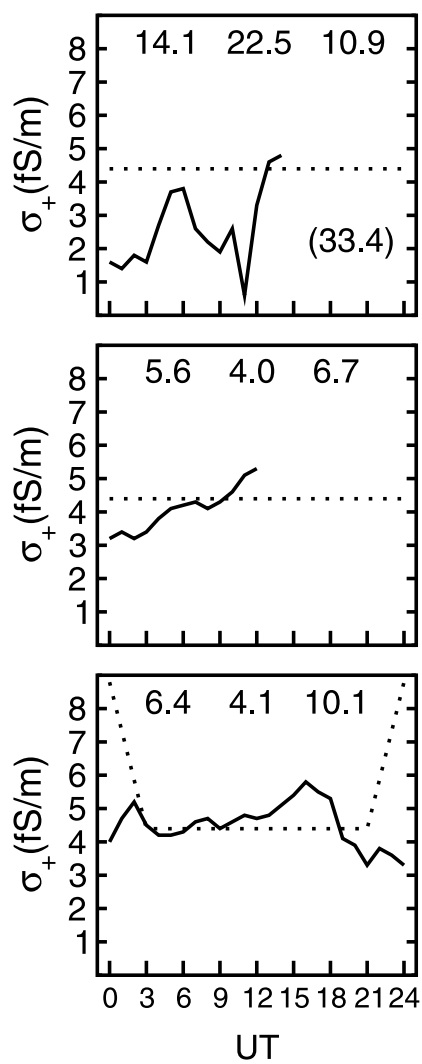

July 2005
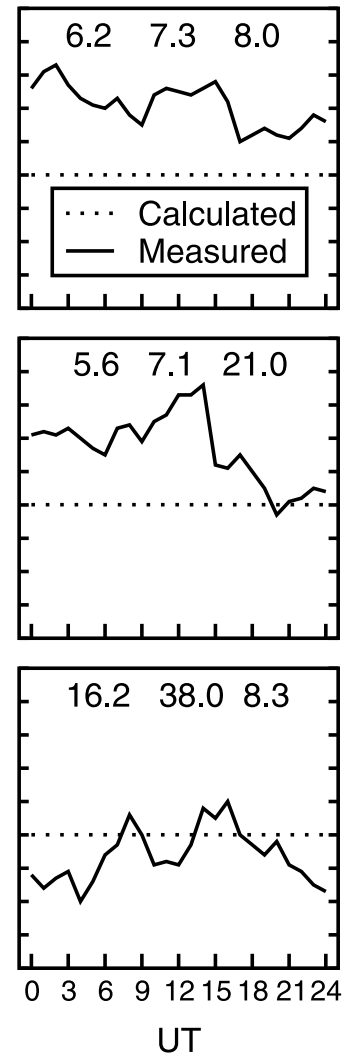

December 2001
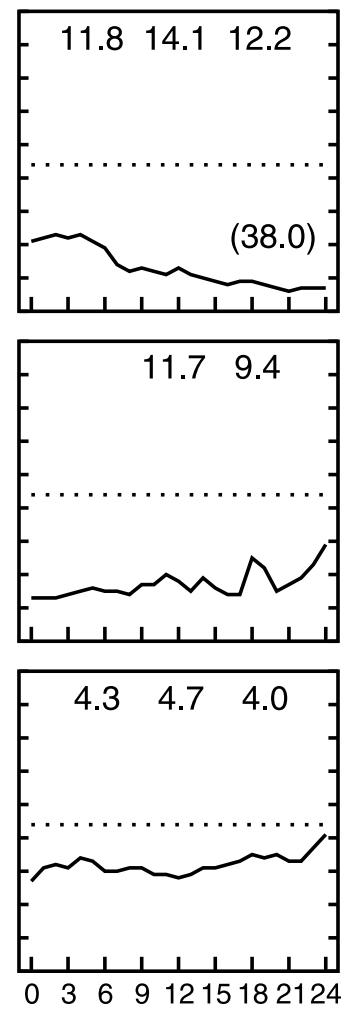

UT
December 2005


Figure 5. The diurnal variation of the positive electric conductivity in the EGATEC circuit branch centred at $22.5^{\circ} \mathrm{E}, 52.5^{\circ} \mathrm{N}$ and observed in Świder on (top) 5, (middle) 15, and (bottom) 25 of July and December 2001 and 2005. Values at the top of each plot are concentrations of aerosol measured at Świder at 6,12 , and $18 \mathrm{UT}$, in units $10^{3} / \mathrm{cm}^{3}$. The two values in brackets in the top row for July 2001 and December 2001 are GADS ground level aerosol concentrations [Hess et al., 1998] for July and December, respectively, used in the conductivity calculations. The total conductivity in the model is twice the positive conductivity.

fair-weather resistance are almost identical but there is a seasonal (July-December) change of the variation pattern. On July days the resistance peaks at 12 UT. On days in December 2001 the resistance peaks at 9 UT and in 2005 is different, maximum value is at 3 UT. We should note here that the ISCCP cloud data at the 3-hour resolution contain average cloud distribution over the period \pm 1.5 hour and therefore our hourly values represent in fact such periods.

\subsection{Current Generated by Clouds}

[58] The net current flowing in each circuit branch is obtained by adding currents from each sub-branch according to equation (8). The geographical distribution is expected to vary over the day and season, as the distribution, surface area and electric activity of the cloud generator changes on these time scales. The average distribution of the upward current at 0, 3, 6, 9, 18 and 21 UT in July and December is shown in Figures 10 and 11. A relationship of the current distribution and activity of the cloud generators concentrated over the three tropical centres in Asia/Maritime Continent, Africa and America [Williams and Sátori, 2004; Williams, 2009] is evident. At a centre maximum activity (i.e. Asia at 9-12 UT, Africa 15-18 UT, America 20-21 UT) the generated current per a circuit branch reaches the highest values and ranges from 10 to $\sim 25 \mathrm{~A}$. Significant currents are also produced over the western Pacific Ocean and over the Atlantic Ocean, east of the South America. In addition, there is also an enhanced current production in December over central Atlantic, at 21 UT. In December, compared to July, the electrical activity moves southward. Moreover, instead of the maximum of the ionospheric potential and total current at 12 UT the December maximum at 9 UT seems to be due to an enhanced current production over the eastern South America and central Atlantic, in addition to the activity over the Maritime Continent. The activity peaks at 21 UT with the largest values of current generated over Brazil and the Maritime Continent.

[59] To analyze in more detail the current contribution to the global current by cloud type we plot the diurnal variation of the current produced by convective and by shower clouds in July and December (an average over the three days, separately for 2001 and 2005 ). The larger part, $\sim 80-85 \%$ is supplied by convective clouds, including $\sim 0.5-1.5 \%$ of lightning current, and the remaining $\sim 15-20 \%$ is supplied 
July 2001
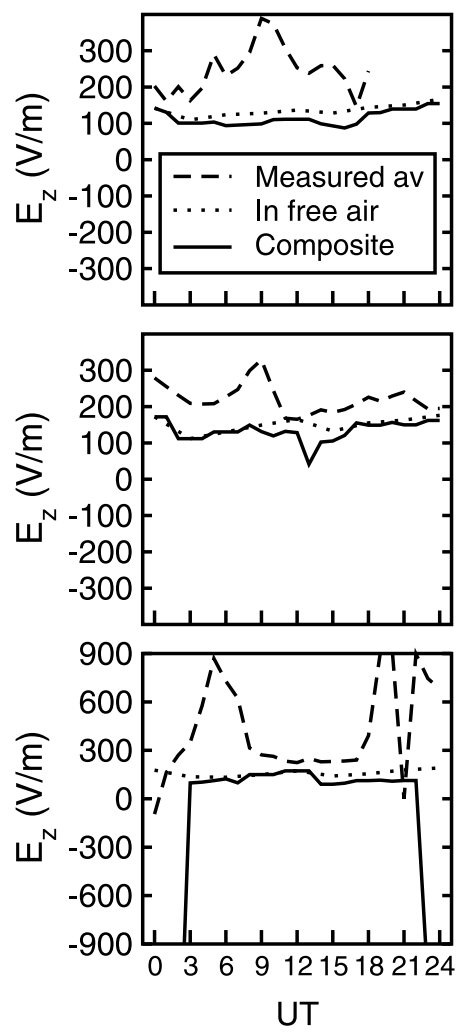

July 2005
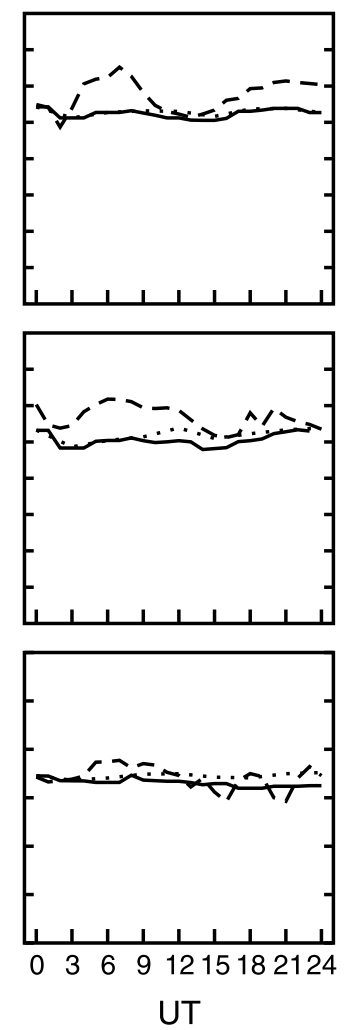

December 2001
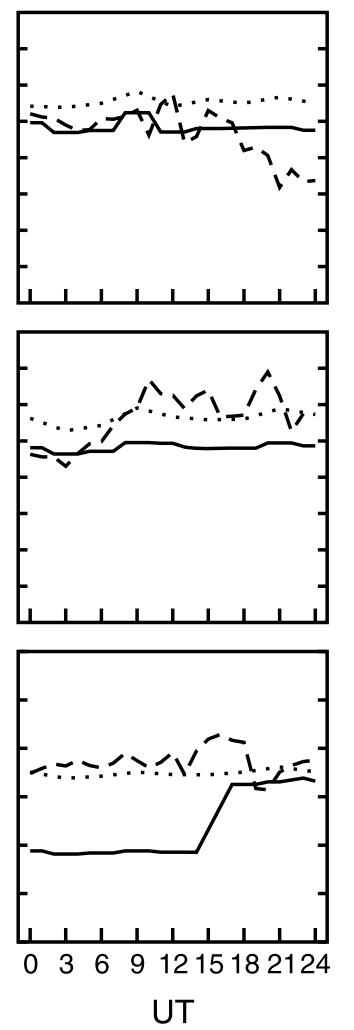

December 2005
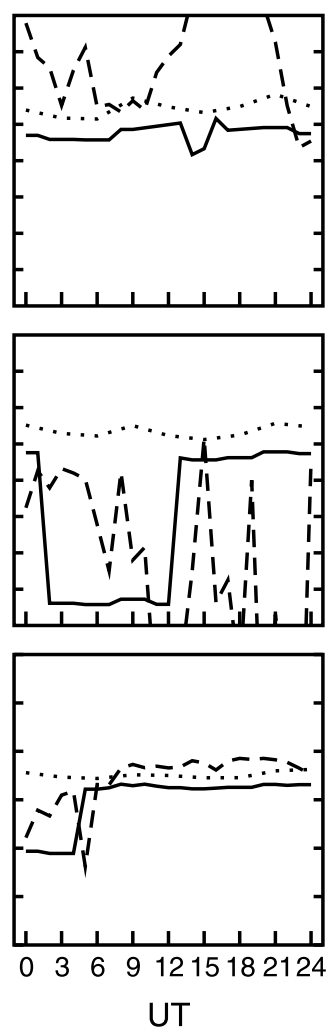

Figure 6. The diurnal variation of the electric field in the EGATEC circuit branch centred at $22.5^{\circ} \mathrm{E}$, $52.5^{\circ} \mathrm{N}$ and observed in Świder on (top) 5, (middle) 15, and (bottom) 25 of July and December 2001 and 2005 .

by shower clouds. In the diurnal variation of the shower cloud current peaks at 12 UT in July, and its minimum occurs then at 3-6 and 18 UT. In December a distinct maximum appears at $9 \mathrm{UT}$, and a minimum at $18 \mathrm{UT}$, there is also another increase at 21-24 UT. The current produced by convective clouds changes similarly but the 21-24 UT (July) and 21 UT (December) maximum is higher relative to the increase in the shower cloud current at this time and the 3 UT minimum is also more pronounced (Figure 12).

[60] By comparing the contribution of the lightning current and the non-lightning current (Figure 13) we conclude that in our model the lightning current has a distinct minimum at 3 UT and a broad maximum over 15-21 UT. The maximum is more pronounced in December than in July and the minimum is lower in December.

\subsection{Current Density and Electric Field in Fair-Weather Area}

[61] The model can also provide the geographic distribution of the current density and potential gradient at the ground (or the electric field) in both foul-weather and fairweather area, including cloud-free area, considered as the ideal fair-weather conditions in both observations and modelling of the GEC. We analyze here particularly seasonal (July-December) differences in these distributions by calculating a difference between an average July and December value (i.e. mean average over six days per each month).
[62] Figure 14 shows maps of July-December differences in the fair-weather electric field. The upper map concerns only cloud-free area (area type 7) and the map on the right show composite values which take into account the presence of the non-generator clouds over any EGATEC cell (i.e. an area-weighted average value for area types $1,2,3,6,7)$. It is clear from these two distributions that differences of the same sign prevail over one hemisphere. In the northern hemisphere over land with higher concentrations of aerosol the model potential gradient is higher in December i.e. during local winter, this is in agreement with what has been observed in Świder over last decades [Kubicki et al., 2007]. According to the model, this is also valid over the Arctic, Greenland and Sahara. The field tends to be higher in July (i.e. during local summer) over oceanic or some less polluted land areas (e.g. North America, central and part of northern Asia and Europe). In the Southern Hemisphere the model potential gradient is higher in July (i.e. during local winter) in the south of Africa, most of Australia and in central South America (polluted land area). The opposite is valid over the rest of the southern hemisphere, i.e. over the ocean and Antarctic. When clouds are included the pattern becomes more patchy and variable, especially over land. The differences in some cases reverse, for example in the Mediterranean area, east coast of the US, and some areas over the Antarctic. These values could be representative as long as the cloud cover and cloud types were close to the characteristic cloud types and cover for the area. Confirming 
July 2001
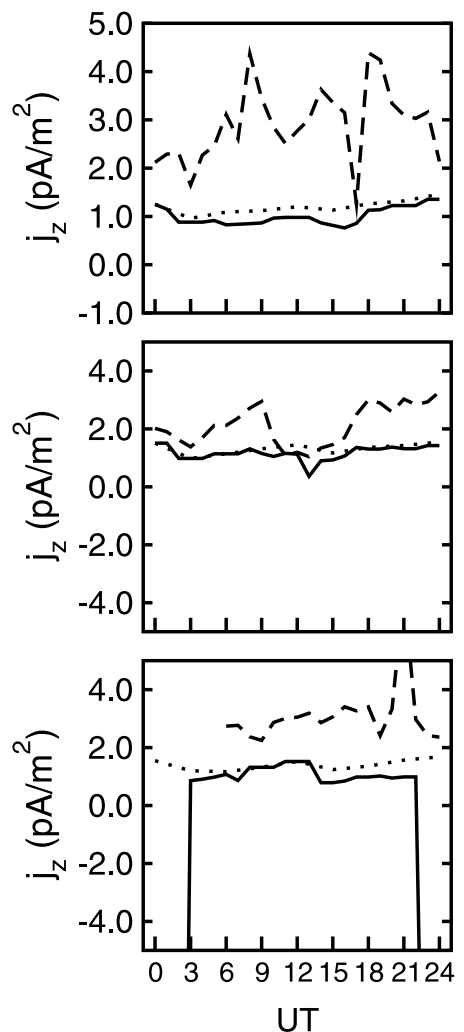

July 2005
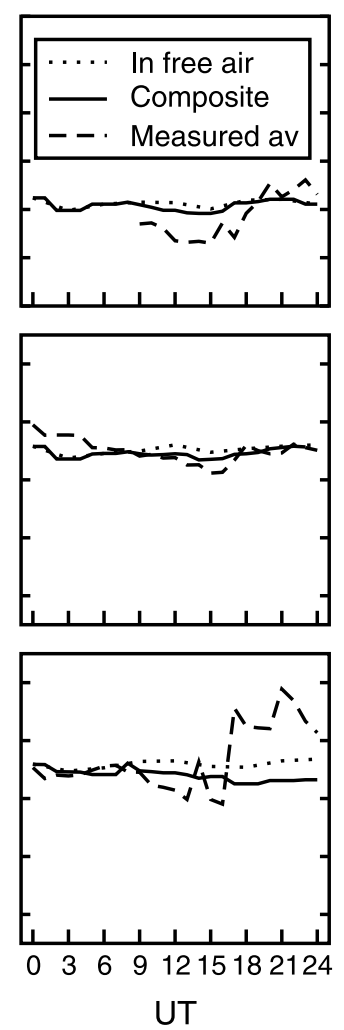

December 2001
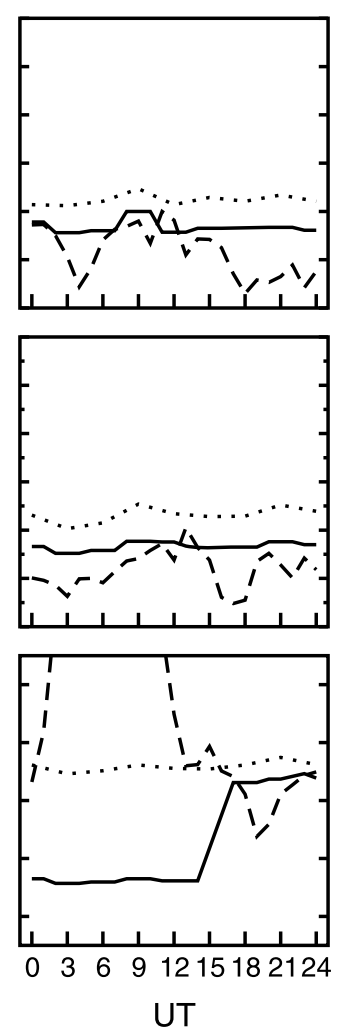

December 2005

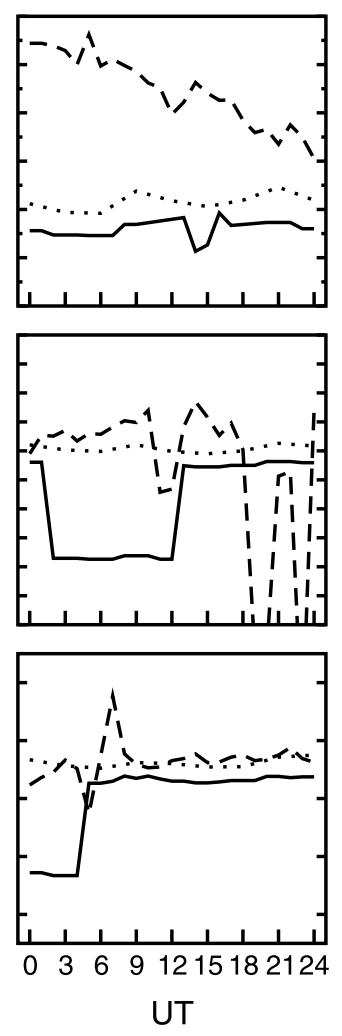

Figure 7. The diurnal variation of the air-Earth current density in the EGATEC circuit branch centred at $22.5^{\circ} \mathrm{E}, 52.5^{\circ} \mathrm{N}$ and observed in Świder on (top) 5, (middle) 15, and (bottom) 25 of July and December 2001 and 2005.

this would require analysis of data over a longer period and we do not analyze it in more detail at this stage.

[63] There are also seasonal differences in the model fairweather air-Earth current density (Figure 15). In this model the density is higher in July over the Arctic, western Europe, India, south-east Asia and south-east coast of Asia, central Africa, and north of the South America. But in the North America, excluding Greenland, and in central Asia the December values are higher. In the southern hemisphere the current density is higher in July over large part of the ocean (southern area down to coast of the Antarctic). In the Antarctic and northern parts of the southern hemisphere ocean the current density is higher in December. Inclusion of clouds complicates the variation pattern, particularly over the Antarctic, North America and western Atlantic and east Asia, where higher values are now associated with July.

[64] In summary the pattern of differences between July and December, on the basis of results from six days for each of these two months, is that in areas of higher aerosol concentration (i.e. mostly over land), July values of the electric field are lower than in December. Higher values of the current density observed in July prevail over the ocean in the southern hemisphere. The seasonal variations predicted by EGATEC are in most cases in agreement with seasonal changes observed at different parts of the globe, investigated by Williams [1994], Adlerman and Williams [1996], and references to earlier papers cited there. For example, our model gives the same (positive/negative) differences between
July and December electric field in 10 out of 11 cases from Adlerman and Williams [1996, Figure 1]; different change was predicted only for Johannesburg (Figure 14). With regard to the current density the model gives similar results in 5 out of 9 cases considered by Williams [1994, Figure 11], including Mauna Loa current density observations analyzed by Adlerman and Williams [1996]. The July maximum of the current density at the branch where Mauna Loa is located is not confirmed by the model, although the model predicts that in July the fair-weather electric field is higher in this area than in December (Figure 15). On the other hand, the model is not necessarily in disagreement with the reanalyzed Carnegie and Maud data by Adlerman and Williams [1996], indicating a maximum of the potential gradient over the northern hemisphere summer, in case the majority of the data that produced those results came from the northern hemisphere ocean.

[65] However, the model predicts larger values of the main, global GEC variables, the ionospheric potential and the total current in December, compared to July. This is contrary to the final conclusion of Williams [1994] and Adlerman and Williams [1996] supported by the observations of the fairweather GEC parameters. Analysis and statistics based on more days is required to confirm this model result. Going back to the results of the observations of the ionospheric potential by Markson [2007], mentioned earlier, and particularly the annual variation, December values are higher than July values but in both case the number of measure- 

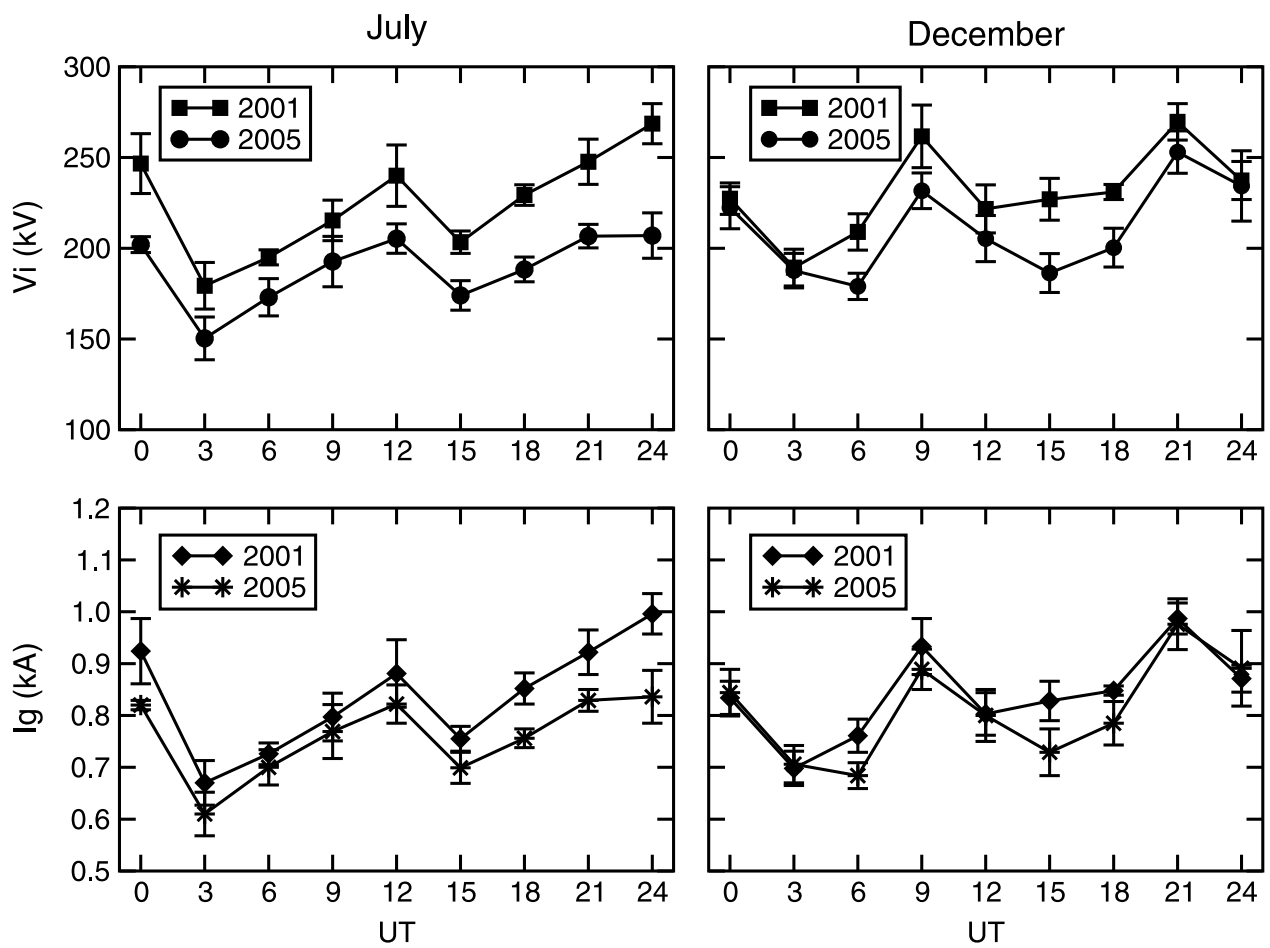

Figure 8. The diurnal variation of (top) mean ionospheric potential and (bottom) global GEC current in July and December 2001 and 2005. The shown values are mean averages of values obtained by equation (7) for 5, 15, and 25 of July or December, separately for 2001 and 2005, for $0,3,6,9,12$, $15,18,21$, and 24 UT. Points on the plot are connected by straight lines. The error bars indicate standard mean deviation.
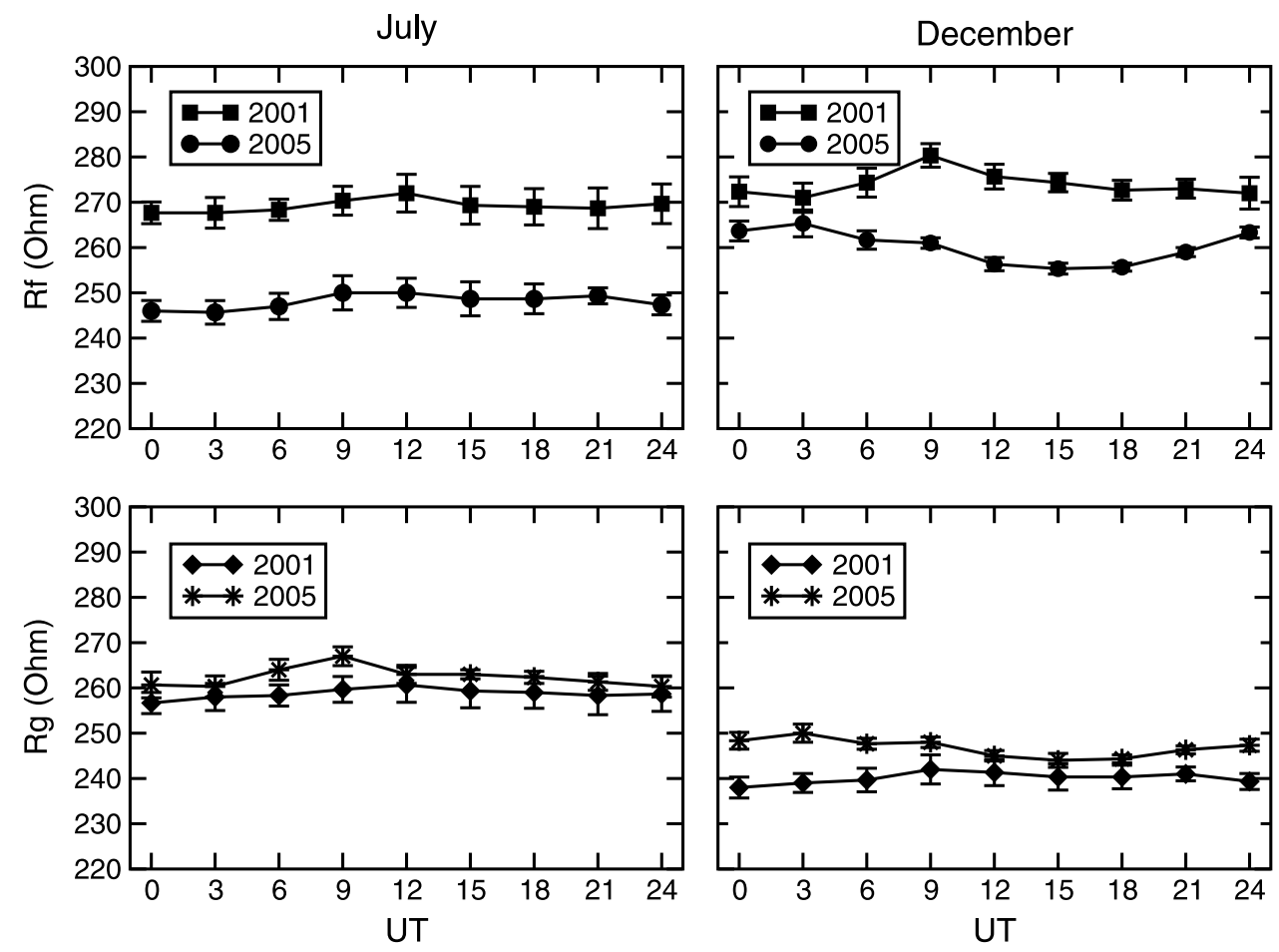

Figure 9. The diurnal variation of mean fair-weather resistance and total atmospheric resistance in July and December 2001 and 2005. 

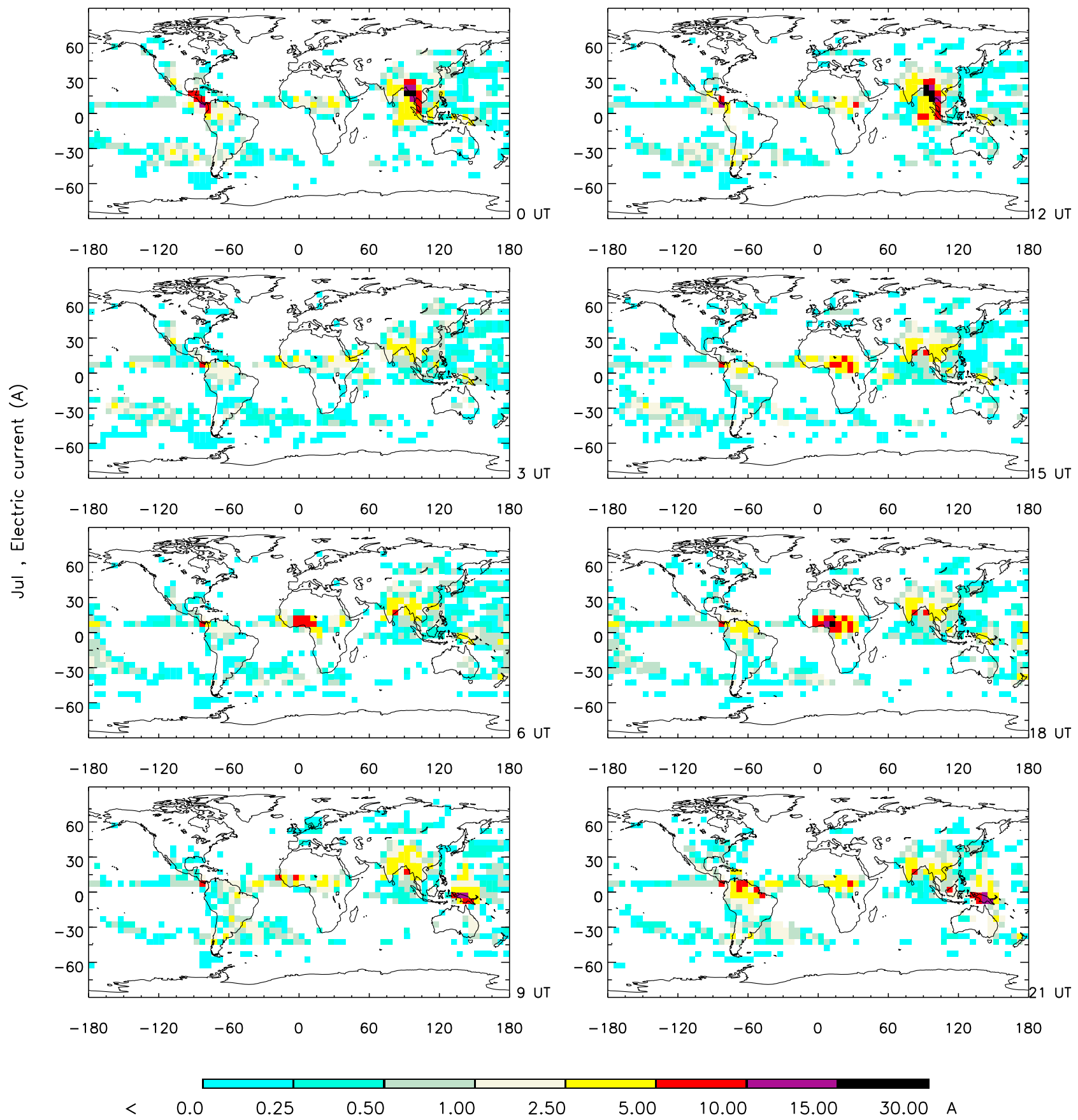

Figure 10. Average global distribution of the electric current generated by cloud generators in July. Data based on model runs from 5, 15, and 25 of July 2001 and 2005.

ments used to calculate the mean value was not very large, nine for July and six for December. The August-October maximum in these data is quite clear though.

\section{Summary and Conclusions}

[66] In this paper we have presented a new, high-resolution engineering model of the global electric circuit. The main features of the model are

[67] 1. Input to the model is based on currently available satellite observations of clouds and cloud properties and activity, and the model includes a novel model of atmospheric conductivity by Tinsley and Zhou [2006].

[68] 2. The model treats the cloud more realistically by taking into account the role of the cloud conductivity in the global resistance and by assessing of the contribution of clouds as current generators on the basis of observed cloud cover and model values of generated current density.

[69] 3. The model allows calculation of the ionospheric potential, the GEC global current and global resistance at 3 hour resolution. These GEC variables can be calculated for each day since at least April 1995. Thus the model 


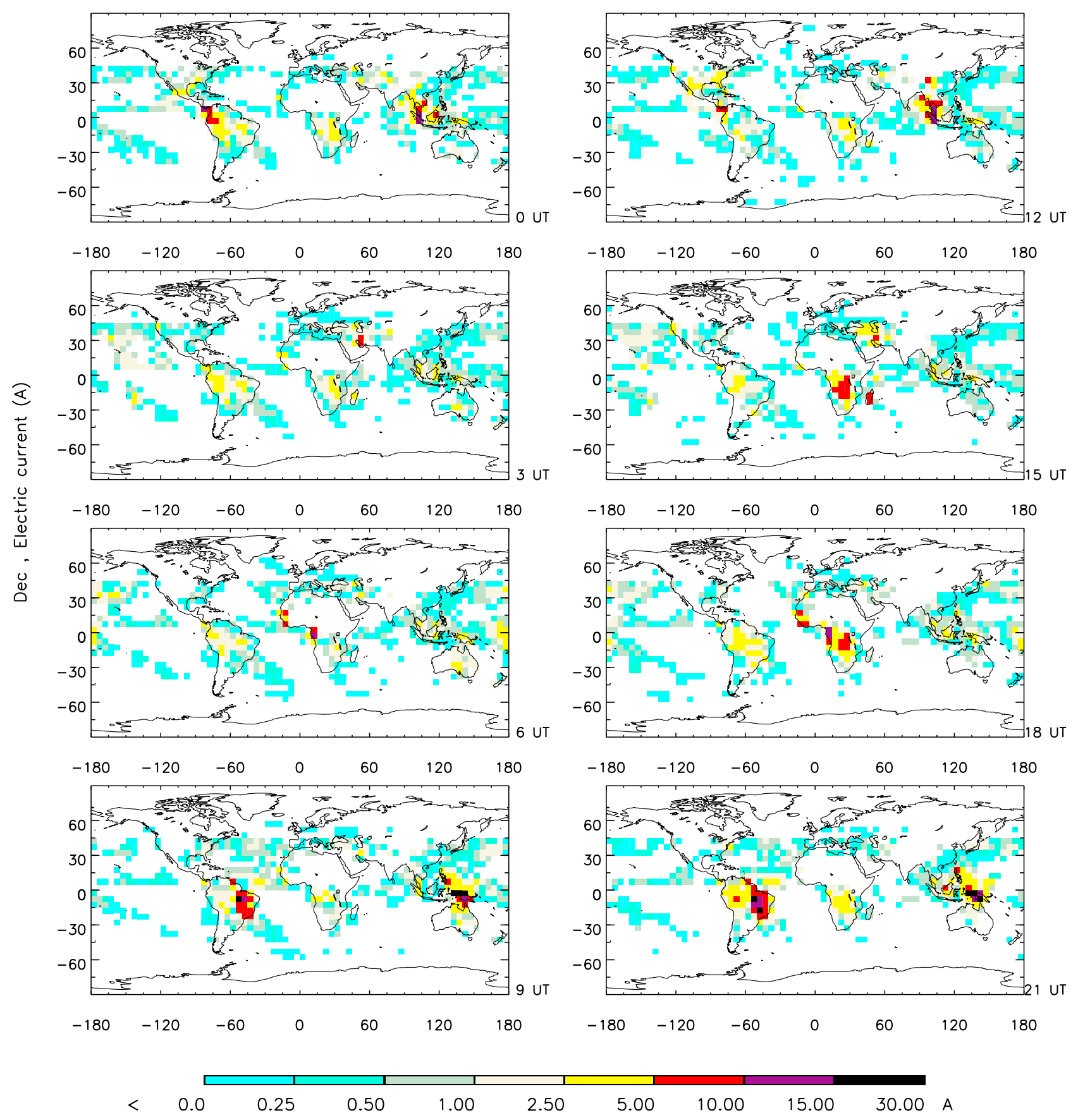

Figure 11. Average global distribution of the electric current generated by cloud generators in December. Data based on model runs from 5, 15, and 25 of December 2001 and 2005.

creates a tool for investigations of the diurnal and seasonal variations of the GEC.

[70] 4. Global distribution of the air-Earth current density and electric field at ground can be obtained at the same time resolution and spatial resolution of $5^{\circ}$ in geographic coordinates.

[71] 5. Composite values of the air-Earth current density and electric field can be calculated to compare model results with observations directly.

[72] 6. Due to the electrical engineering representation of the GEC by an equivalent current there are standard algorithms or software created for finding a solution of the circuit.

[73] 7. The model enables various parametric studies.

[74] By using a season-dependent conductivity and cloud current generator model we obtained some preliminary results on the diurnal and seasonal variations of the Earth's global atmospheric circuit. The model indicates larger ionospheric potential and global current in December over July. This is opposite to what has been concluded about the GEC maximum from observations more recently [Adlerman and Williams, 1996; Williams, 2009]. However, the model 

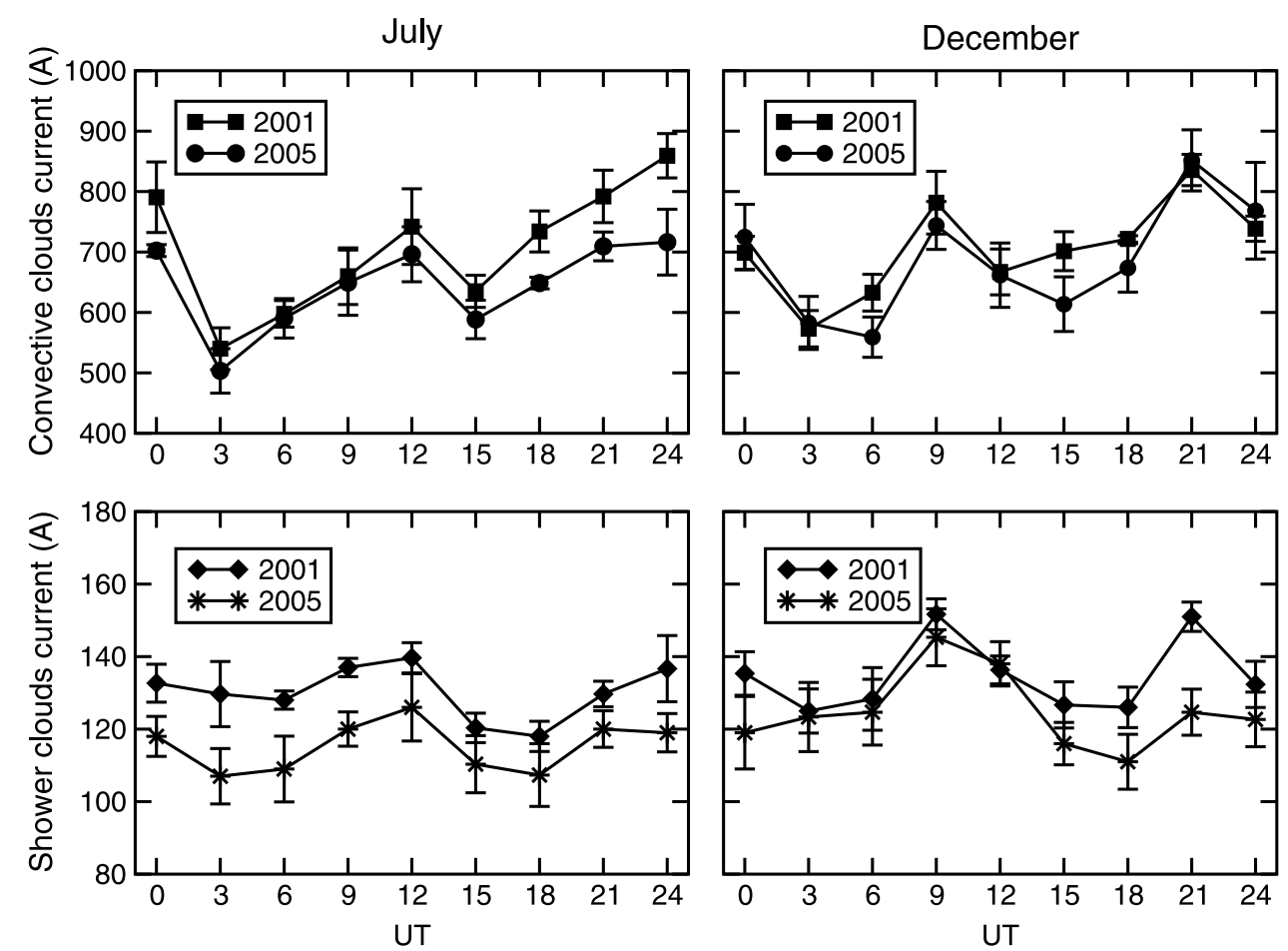

Figure 12. The diurnal variation of mean electric current produced by convective and shower clouds in July and December 2001 and 2005.

does correctly predict the observed change of the potential gradient from July to December for a number of location over the globe, and in about half the cases the prediction about the change in the air-Earth current density is also correct.
[75] As far as the diurnal variation is concerned our model predicts a maximum of the GEC at $21 \mathrm{UT}$ and a minimum at 3 UT, which is in agreement with observations and also confirms more significant contribution to the GEC from the Maritime Continent and South America rather than Africa,
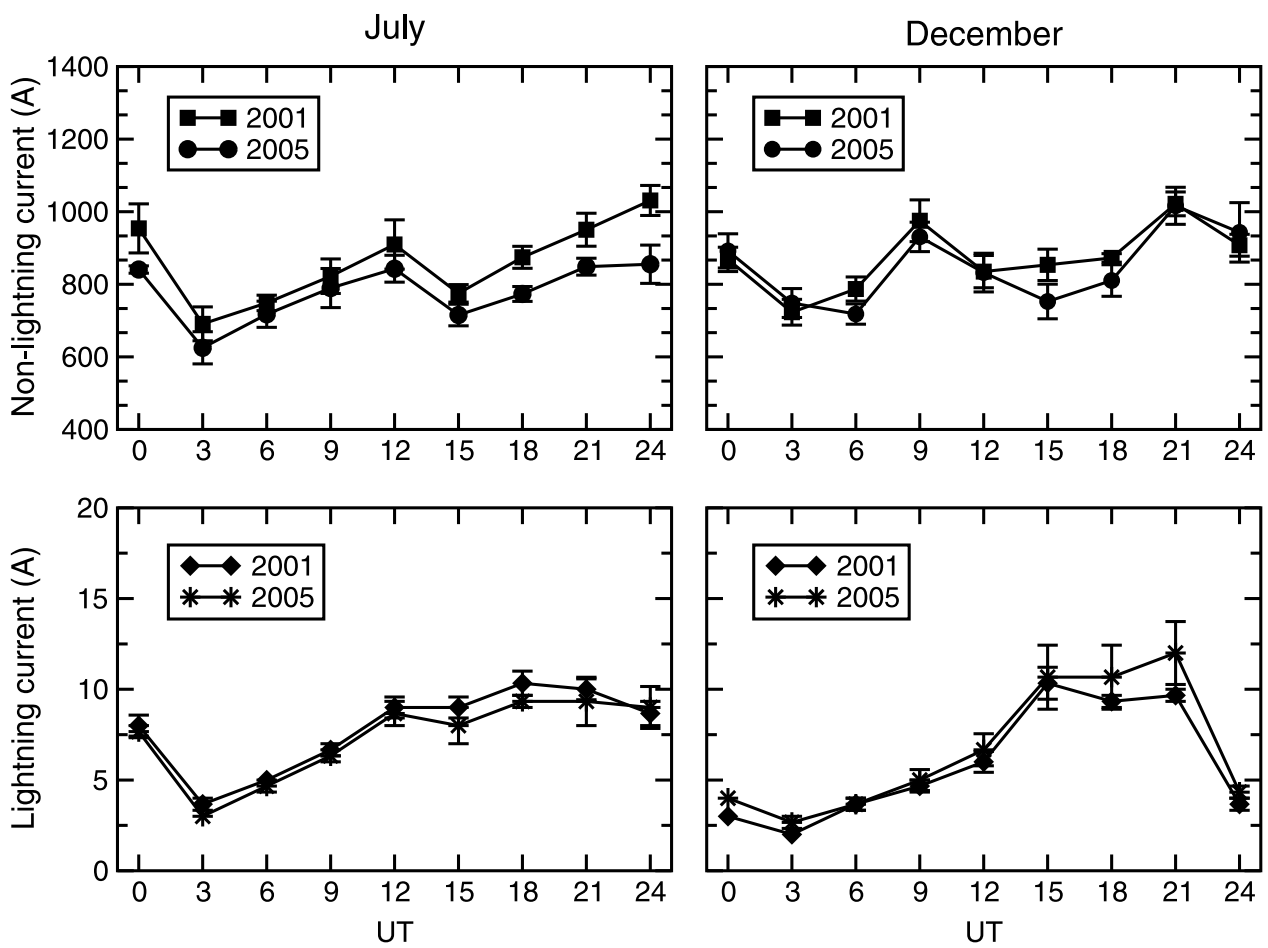

Figure 13. The diurnal variation of mean lightning and non-lightning current in July and December 2001 and 2005. 


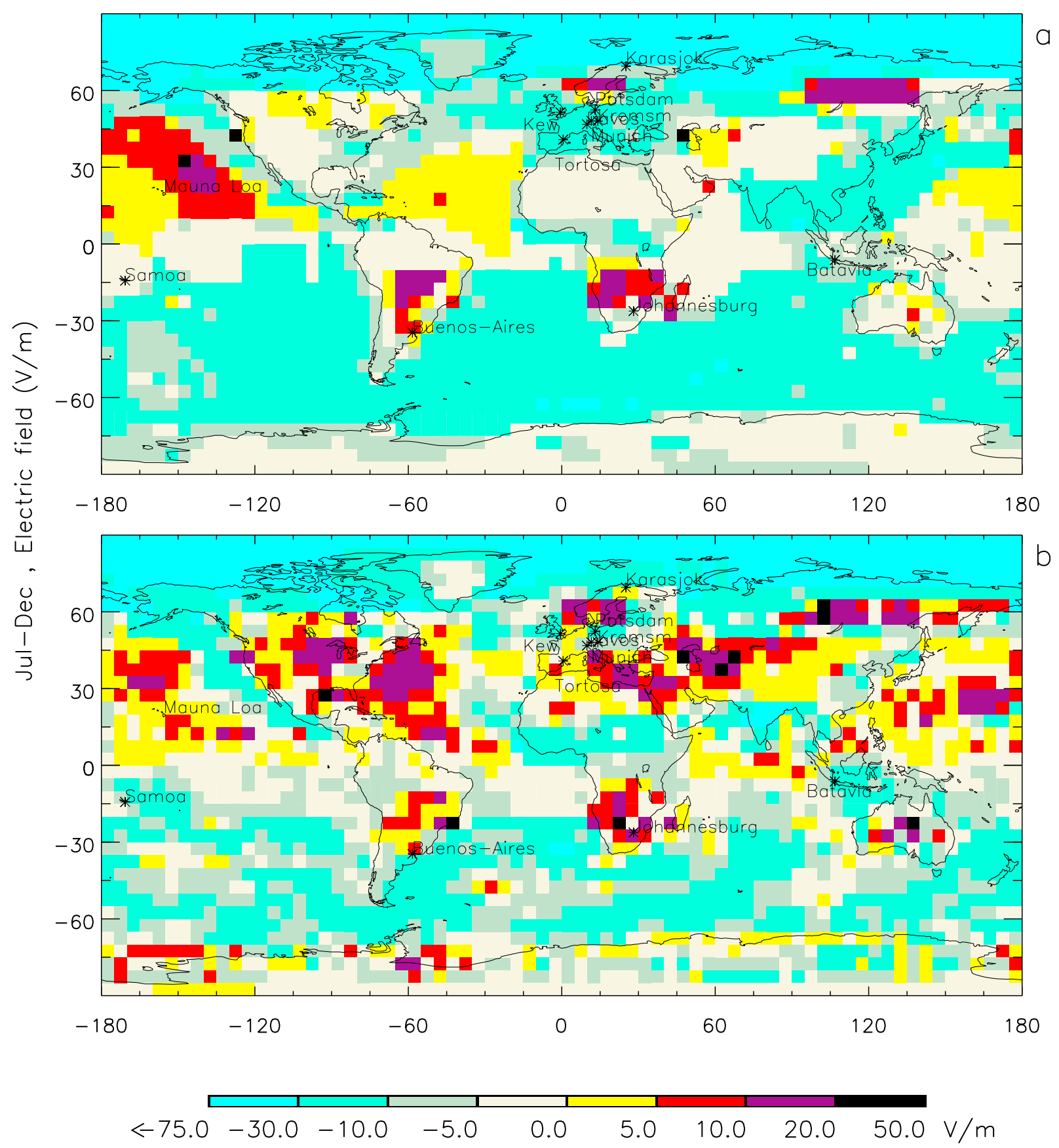

Figure 14. Seasonal (July December) differences in the distribution of the fair-weather electric field. (a) Cloud-free area (7), and (b) composite values for cloudy area (1, 2, 3, 6, 7). Marked locations refer to stations from the survey of the seasonal variations of the observed electric field current density shown by Adlerman and Williams [1996], Figure 1. The model differences are in agreement in 10 cases out of 11 (all except Johannesburg).

which occurs to be predominant in lightning [Christian et al., 2003; Bailey et al., 2007; Mach et al., 2010]. In fact, the maximum African electrical activity (15-18 UT), is not very evident in our model results, and definitely not as strong as in some records of the observed diurnal variation of potential gradient [Chalmers, 1958]. This may indicate that some of our assumptions made about the electrified cloud generators require revision, e.g. the cloud altitude range, current densities, charge structure or the contribution of lightning. In future we consider the following directions of the development of this GEC model:

[76] 1. Improving the spatial resolution.

[77] 2. Using input from observed aerosol concentrations and properties.

[78] 3. Improving the cloud generator model and cloud conductivity model. 

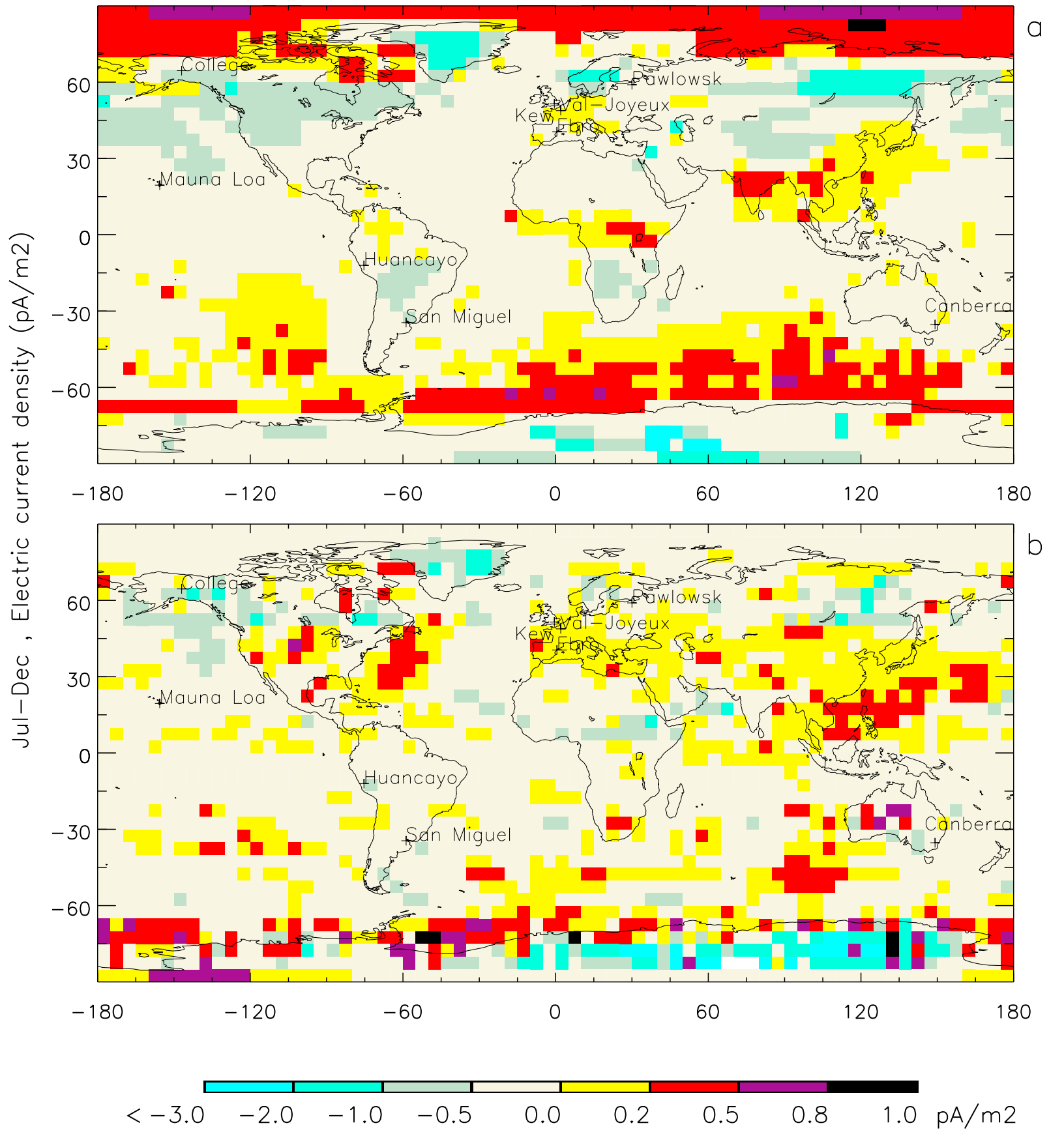

Figure 15. Seasonal (July December) differences in the distribution of the fair-weather air-Earth current density. (a) Cloud-free area (7), and (b) composite values for cloudy area (1, 2, 3, 6, 7). Marked locations refer to stations from the survey of the observed seasonal variations of the current density by Williams [1994], Figure 11 and Mauna Loa, analyzed by Adlerman and Williams [1996] The model differences are in agreement in 5 cases (College, Pawlowsk, Val-Joyeux, Huancayo, and San Miguel) out of 9.

[79] 4. Modelling the coupling of the lower atmosphere current system to the ionosphere-magnetosphere current system.

[80] We also need to perform more model runs, using data from longer periods, to confirm or review the results that we have obtained so far.

[81] Development of cloud models in the GEC should include improved cloud conductivity model for various types of clouds and improved modelling of the current generation and charge structure in various types of clouds. More observations of the cloud electrical activity and modelling is necessary to create better electrical representations of clouds in the GEC. The new models are likely to be based on the cloud microphysical parameters. The models should be more realistic but at the same time enable to create representations of the cloud electrical activity over the 
whole globe on the basis of data which can be available to create such representations, e.g. the satellite ISCCP data or other data sets available.

[82] Although the current generated by lightning discharges seems not to contribute significantly to the circuit [Thomas et al., 2009; Mach et al., 2009] the role of the intra-cloud discharges in the lightning current budget is not well determined. Also, the average charge transferred by the lightning is a constant in our model for all types of convective systems which may be a different value. These topics require further investigation and modelling efforts. Further investigation is also required to the role and contribution of electrified or precipitation or corona discharges, and how this can be explicitly represented in GEC models.

[83] By including the coupling of the lower atmosphere current system we would like to model the effects of the non-equipotential ionosphere and of the ionospheric and magnetospheric current generators. That new model version should be able to put more new light on the two different hypothesis by [Kartalev et al., 2004] and Williams and Sátori [2004] explaining the dominance of the South American tropical centre in the diurnal activity of the GEC.

\section{Appendix A: ISCCP Data Fit Procedure}

[84] This procedure is required to interpolate ISCCP cloud data over these ISCPP cells where all or some required ISCCP cloud variables are not determined. This allows to obtain complete distributions of these variables for input to the GEC model.

[85] The interpolation of ISCCP data can be performed in the time and spatial domain and normally starts with the interpolation in the time domain. First, the data set of interest at $t_{0}=0,3,6$.. is read simultaneously with preceding and following data sets at $t_{0}-12 \mathrm{~h}, t_{0}-9 \mathrm{~h}, t_{0}-6 \mathrm{~h}, t_{0}-3 \mathrm{~h}$, $t_{0}+3 \mathrm{~h}, t_{0}+6, t_{0}+9 \mathrm{~h}, t_{0}+12 \mathrm{~h} ; \pm 12$ hours is the furthest we consider the interpolation is reliable. Initially it is assessed in which cells of the $t_{0}$ data set the required ISCCP IR variables (fraction of cloud-free area and area covered by the three IR cloud categories, cloud top altitude and precipitable water at the three levels) and VIS-adjusted variables (percentage of area covered by nine VIS cloud categories and cloud-free area) are not determined. Next, the fraction area of IR or VIS clouds for every cell where either IR or VIS cloud variables are not determined are found by the following procedure:

[86] 1. The data in the read data sets are checked whether an IR set of variables is determined in the same cell in any preceding data set at $t<t_{0}$ and which of them is the nearest one, and the same over the following data sets at $t>t_{0}$. The relevant IR-variables sets $\left\{P_{j}\right\}\left(t_{1}^{I R}\right)$ and $\left\{P_{j}\right\}\left(t_{2}^{I R}\right), t_{1}^{I R}<t_{0}<$ $t_{2}^{I R}$ are stored for use in following fitting procedures. If such $t_{1}^{I R}$ and $t_{2}^{I R}$ are found the cell is tagged as "IR-fit-able".

[87] 2. The same is checked and determined for VIS variables. If $t_{1}^{V I S}$ and $t_{2}^{V I S}$ can be found the cell is tagged as "VIS-fit-able".

[88] 3. In case neither IR or VIS variables are determined in the cell at $t_{0}$ and if the cell is only "IR-fit-able" a procedure called FitIR2IR follows, and procedure FitVIS2VIS if the cell is "VIS-fit-able".

[89] 4. In case only VIS variables are not determined and the cell is "VIS-fit-able" then if $\left|t_{2}^{V I S}-t_{1}^{V I S}\right|<=\left|t_{2}^{I R}-t_{1}^{I R}\right|$ the procedure FitVIS2VIS is called otherwise a procedure called FitVIS2VISbyIR applies.

[90] 5. In the FitVIS2VIS procedure, if at $t_{0}$ IR variables were not determined at the start they are now found from the appropriate newly calculated VIS variables.

[91] Procedures FitIR2IR, FitVIS2VIS and FitVIS2VISbyIR are constructed similarly, except in the latter case only clouds from the levels present in the IR data of cells at $t_{1}^{I R}$ and $t_{2}^{I R}$ are allowed in the fitting of VIS variables from $t_{1}^{V I S}$ and $t_{2}^{V I S}$ to $t_{0}$.

[92] In each case a specified set of variables $P=$ $\left\{P_{i}\right\}: \Sigma_{i} P_{i}=1$ must be found for the cell. In FitIR2IR $P$ has four elements (fraction area of 3 cloud categories and cloudfree area). In FitVIS2VIS $P$ has ten elements (fraction area of 9 cloud categories and cloud-free area), and in FitVIS2VISbyIR $P$ is a subset of this ten-element set. $\left\{P_{i}\right\}\left(t_{0}\right)$ are found on the basis of $\left\{P_{i}\right\}\left(t_{1}\right)$ and $\left\{P_{i}\right\}\left(t_{2}\right)$ as follows:

[93] 1. An index $j$ of the variable $P_{j}$ occupying the most of the surface area in both $\left\{P_{i}\right\}\left(t_{1}\right)$ and $\left\{P_{i}\right\}\left(t_{1}\right)$ i.e. such as $P_{j}(t 1)+P_{j}(t 2)$ is the largest, is found.

[94] 2. A new $P_{j}$ value at $t_{0}$ is found by a linear relation

$$
P_{j}\left(t_{0}\right)=P_{j}\left(t_{1}\right)+\frac{P_{j}\left(t_{2}\right)-P_{j}\left(t_{1}\right)}{t_{2}-t_{1}}\left(t_{0}-t_{1}\right)
$$

[95] 3. The lately calculated variable $P_{j}$ is removed from $P$.

[96] 4. Instructions 1.,2.,3. are repeated until there is only one variable left in the subset $P$ or the sum of newly calculated values becomes overloaded, i.e. $\Sigma_{j} P_{j}>1$.

[97] 5. If $\Sigma_{j} P_{j}$ is overloaded then $P_{j}(t 0)$ is replaced by $1-\Sigma_{j} P_{j}$ and all remaining $P_{i}$ in the set $P$ are set to zero.

[98] 6. In case there is only one variable $P_{i}$ left in the set $P$ the following condition are checked: if after last time $\Sigma_{j} P_{j}$ was overloaded then the last $P_{j}$ is set to $1-\Sigma_{j} P_{j}$ and $P_{l}\left(t_{0}\right)=0$ (previous case). Otherwise, at first $P_{l}$ is estimated by equation (A1). If adding the new value to $\Sigma_{j} P_{j}$ overloads it then $P_{l}$ is set to $1-\Sigma_{j} P_{j}$. In case $\Sigma_{j} P_{j}+P_{i}<1$ then the remaining fraction $1-\left(\Sigma_{j} P_{j}+P_{i}\right)$ is added to the cloud-free fraction, or, alternatively, all values are scaled proportionally to make $\Sigma_{i} P_{i}=1$. The first choice is preferred in the current algorithm version.

[99] If necessary, new values for the cloud top level and three precipitable water levels are fitted separately, according to equation (A1).

[100] After the procedure in the time domain the whole ISCPP grid is checked once again if IR variables are determined in all cells. If still there are empty cells then the procedure starts in the spatial domain. In the spatial domain analogous procedures WeaveIR2IR and WeaveVIS2VIS follow. The main change in the procedures is that variables are now interpolated by averaging values from adjacent cells over the same ISCCP grid, and equation (A2) is used instead of equation (A1).

$$
P_{j}\left(t_{0}\right)=\frac{1}{n} \sum_{k=1}^{n} P_{j}^{k}\left(t_{0}\right), \quad n>=4,3
$$

[101] The spatial averaging is performed first for IR variables and next for VIS variables. In addition, in the first step, the procedure is applied if at least one adjacent cell from both the north, south, west, and east of the cell can be 
used for the interpolation (i.e. the set of necessary variables is determined in each of those cells). In the next step if the set of necessary ISCCP data is still not complete it is allowed that adjacent cells from just three directions are used. In practice the interpolation in the time domain is usually sufficient to complete the whole ISCCP data set.

[102] Equations (A1) and (A2) may underestimate (overestimate) a variable $P_{i}$ in case the real value was a local maximum (minimum). In future the whole procedure may be developed and more complicated interpolation method found, for example, based on data from more cells in the time domain or by combining interpolation in time and space simultaneously.

[103] Acknowledgments. ISCCP D1 data sets were obtained from the NASA Langley Research Center Atmospheric Science Data Center, http://eosweb.larc.nasa.gov. OTD/LIS Gridded data sets were obtained from the NASA Global Hydrology and Climate Center, http://thunder. nsstc.nasa.gov. TRMM 3B42 data sets were obtained from the NASA Goddard Distributed Active Archive Center, http://daac.gsfc.nasa.gov. GADS data sets and software were obtained from http://www.lrz-muenchen.de/ uh234an/www/radaer/gads.html. A. Odzimek acknowledges funding from the European Commission through the Marie Curie European Reintegration Grant PERG-GA-2007-203298 within the 7th European Community Framework Programme (FP7)

\section{References}

Adlerman, E. J., and E. R. Williams (1996), Seasonal variation of global electric circuit, J. Geophys. Res., 101(D23), 29,679-29,688.

Anderson, R. V. (1966), Measurements of total current density above active snowstorms, J. Atmos. Terr. Phys., 28, 789-790.

Bailey, J. C., R. J. Blakeslee, D. E. Buechler, and H. J. Christian (2007), Diurnal lightning distributions as observed by the Opptical Transient Detector (OTD) and the Lightning Imaging Sensor (LIS), paper presented at 13th International Conference on Atmospheric Electricity, Int. Comm. on Atmos. Electr., Beijing.

Chalmers, J. A. (1958), The electricity of nimbo-stratus clouds, in Recent Advances in Atmospheric Electricity, edited by L. G. Smith, pp. 309315, Pergamon, New York.

Christian, H. J., R. J. Blakeslee, S. J. Goodman, D. M. Mach, M. F. Steward, D. E. Buechler, W. J. Koshak, J. M. Hall, K. T. Driscoll, and D. J. Boccippio (1999), The Lightning Imaging Sensor, NASA Conf. Publ., 209261, 746-749.

Christian, H. J., et al. (2003), Global frequency and distribution of lightning as observed from space by the Optical Transient Detector, J. Geophys. Res., 108(D1), 4005, doi:10.1029/2002JD002347.

Harrison, R. G. (2004), The global atmospheric electrical circuit and climate, Surv. Geophys., 25(5-6), 441-484, doi:10.1007/s10712-004-5439-8.

Harrison, R. G., and K. A. Nicoll (2008), Air-Earth current density measurements at Lerwick; Implications for seasonality in the global electric circuit, Atmos. Res., 89, 181-193.

Hays, P. B., and R. G. Roble (1979), A quasi-static model of global atmospheric electricity: 1. The lower atmosphere, J. Geophys. Res., 84(A7), 3291-3305.

Hedin, A. E. (1991), Extension of the MSIS thermospheric model into the middle and lower atmosphere, J. Geophys. Res., 96(A2), 1159-1172.

Hess, M., P. Koepke, and I. Schult (1998), Optical properties of aerosols and clouds: The software package OPAC, Bull. Am. Meteorol. Soc., 79(5), 831-844.

Houze, R. A., Jr. (1993), Cloud Dynamics, 573 pp., Academic, San Diego, Calif.

Imyanitov, I. M., and K. S. Shifrin (1962), Present state of research on atmospheric electricity (in Russian), Sov. Phys. Usp., 5(2), 292-322.

Imyanitov, I. M., E. W. Chubarina, and J. W. Szwarc (1974), Cloud Electricity (in Polish), 139 pp., Panstwowe Wydawnictwo Naukowe, Warsaw.

Kartalev, M. D., M. J. Rycroft, M. Fuellekrug, V. O. Papitashvili, and V. I. Keremidarska (2004), A possible explanation for the dominant effect of South American thunderstorms on the Carnegie curve, J. Atmos. Sol. Terr. Phys., 68, 457-468, doi:10.1016/j.jastp.2005.05.012.

Kubicki, M. (2005), Results of atmospheric electricity and meteorological observations at S. Kalinowski Geophysical Observatory at Świder, Publ. Inst. Geophys. Pol. Acad. Sci., D, 71(391), 3-72.

Kubicki, M., S. Michnowski, and B. Myslek-Laurikainen (2007), Seasonal and daily variations of atmospheric electricity parameters registered at the
Geophysical Observatory at Świder (Poland) during 1965-2000, paper presented at 13th International Conference on Atmospheric Electricity, Int. Comm. on Atmos. Electr., Beijing.

Kummerow, C., W. Barnes, T. Kozu, J. Shiue, and J. Simpson (1998), The Tropical Rainfall Measuring Mission (TRMM) sensor package, J. Atmos. Oceanic Technol., 15, 809-817.

Lyons, W. A. (2006), The meteorology of transient luminous events-An introduction and overview, in Sprites, Elves, and Intense Lightning Discharges, edited by M. Füllekrug, E. A. Mareev, and M. J. Rycroft, pp. 19-56, Springer, Dordrecht, Netherlands.

MacGorman, D., and W. D. Rust (1998), The Electrical Nature of Storms, 422 pp., Oxford Univ. Press, New York.

Mach, D. M., R. J. Blakeslee, M. G. Bateman, and J. C. Bailey (2009), Electric fields, conductivity, and estimated currents from aircraft overflights of electrified clouds, J. Geophys. Res., 114, D10204, doi:10.1029/ 2008JD011495.

Mach, D. M., R. J. Blakeslee, M. G. Bateman, and J. C. Bailey (2010), Comparisons of total currents based on storm location, polarity, and flash rates derived from high-altitude aircraft overflights, J. Geophys. Res., 115, D03201, doi:10.1029/2009JD012240.

Makino, M., and T. Ogawa (1984), Responses of atmospheric electric field and air-Earth current to variations of conductivity profiles, J. Atmos. Terr. Phys., 46, 431-445.

Markson, R. (1985), Aircraft measurements of the atmospheric electrical global circuit during the period 1971-1984, J. Geophys. Res., 90(D4), $5967-5977$.

Markson, R. (2007), The global circuit intensity: Its measurement and variation over the last 50 years, Bull. Am. Meteorol. Soc., 88, 1-19.

Nicoll, K. A., and R. G. Harrison (2009), Electrical charge on nonthunderstorm cloud edges, paper presented at Environmental Electrostatics Meeting 3, Inst. of Phys., London.

Nisbet, J. S. (1983), A dynamic model of thundercloud electric fields, J. Atmos. Sci., 40, 2855-2873.

Odzimek, A., and M. Lester (2009), Modelling the Earth's global atmospheric electric circuit-Development, challenges and directions, $P u b l$. Inst. Geophys. Pol. Acad. Sci., D, 73(412), 37-53.

Price, C., J. Penner, and M. Prather (1997), $\mathrm{NO}_{x}$ from lightning: 2. Constraints from the global atmospheric electric circuit, J. Geophys. Res., 102(D5), 5943-5951.

Rakov, V. A., and M. A. Uman (2003), Lightning: Physics and Effects, 687 pp., Cambridge Univ. Press, New York.

Rossow, W. B., and R. A. Schiffer (1991), ISCCP cloud data products, Bull. Am. Meteorol. Soc., 71, 2-20.

Rossow, W. B., and R. A. Schiffer (1999), Advances in understanding clouds from ISCCP, Bull. Am. Meteorol. Soc., 80, 2261-2288, doi:10.1175/1520-0477.

Rossow, W. B., A. W. Walker, D. E. Beuschel, and M. D. Roiter (1996), International satellite cloud climatology project (ISCCP) documentation of new cloud datasets, $W M O / T D$ 737, 115 pp., World Meteorol. Org., Geneva.

Rycroft, M. J., and A. Odzimek (2010), Effects of lightning and sprites on the ionospheric potential, and threshold effects on sprite initiation, obtained using an analog model of the global atmospheric electric circuit, J. Geophys. Res., 115, A00E37, doi:10.1029/2009JA014758.

Rycroft, M. J., S. Israelsson, and C. Price (2000), The global atmospheric electric circuit, solar activity and climate change, J. Atmos. Sol. Terr. Phys., 62, 1563-1576.

Rycroft, M. J., A. Odzimek, N. F. Arnold, M. Fullekrug, A. Kulak, and T. Neubert (2007), New model simulations of the global atmospheric electric circuit driven by thunderstorms and electrified shower clouds: The roles of lightning and sprites, J. Atmos. Sol. Terr. Phys., 69, 2485-2509.

Sapkota, B. K., and N. C. Varshneya (1990), On the global atmospheric electric circuit, J. Atmos. Terr. Phys., 52, 1-22.

Soula, S., and S. Chauzy (1997), Charge transfer by precipitation between thundercloud and ground, J. Geophys. Res., 102(D10), 11,061-11,069.

Stolzenburg, M., and T. C. Marshall (2008), Charge structure and dynamics in thunderstorms, Space Sci. Rev., 137(1-4), 355-372, doi:10.1007/ s11214-008-9338-z.

Swider, W. (1985), Ionic mobility, mean mass, and conductivity in the middle atmosphere from near ground level to $70 \mathrm{~km}$, Radio Sci., 23(3), 389-399.

Thomas, J. N., R. H. Holzworth, and M. P. McCarthy (2009), In situ measurements of contributions to the global electrical circuit by a thunderstorm in southeastern Brazil, Atmos. Res., 91, 153-160, doi:10.1016/j. atmosres.2008.03.026.

Tinsley, B. A. (2008), The global atmospheric electric circuit and its effects on cloud microphysics, Rep. Prog. Phys., 71(6), 066801, doi:10.1088/ 0034-4885/71/6/066801. 
Tinsley, B. A., and L. Zhou (2006), Initial results of a global circuit model with variable stratospheric and tropospheric aerosols, J. Geophys. Res., 111, D16205, doi:10.1029/2005JD006988.

Willett, J. C. (1979), Solar modulation of the supply current for atmospheric electricity?, J. Geophys. Res., 84(C8), 4999-5002.

Williams, E. R. (1994), Global circuit response to seasonal variations in global surface air temperature, Mon. Weather Rev., 122(8), 1917-1929, doi:10.1175/1520-0493.

Williams, E. R. (2009), The global electrical circuit: A review, Atmos. Res., 91, 140-152, doi:10.1016/j.atmosres.200805.018.

Williams, E. R., and S. J. Heckman (1993), The local diurnal variation of cloud electrification and the global diurnal variation of negative charge on the Earth, J. Geophys. Res., 98(D3), 5221-5234.

Williams, E. R., and G. Sátori (2004), Lightning, thermodynamic and hydrological comparison of the two tropical continental chimneys, J. Atmos. Sol. Terr. Phys., 66, 5221-5234.
Wilson, C. T. R. (1920), Investigation on lightning discharges and on the electric field of thunderstorms, Philos. Trans. R. Soc. A, 211, 73-115.

Wormell, T. W. (1930), Vertical electric currents below thunderstorms and showers, Proc. R. Soc. A, 127, 567-590.

Wormell, T. W. (1953), Atmospheric electricity: Some recent trends and problems, Q. J. R. Metorol. Soc., 79, 474-489.

Zhou, L., and B. A. Tinsley (2007), Production of space charge at the boundaries of layer clouds, J. Geophys. Res., 112, D11203, doi:10.1029/2006JD007998.

M. Kubicki and A. Odzimek, Department of Atmospheric Physics, Institute of Geophysics, Polish Academy of Sciences, Ks. Janusza 64, 01-425 Warsaw, Poland. (aodzimek@igf.edu.pl)

M. Lester, Department of Physics and Astronomy, University of Leicester, University Road, Leicester LE1 7RH, UK. 